\title{
Proyectos de cárceles en la Real Academia de Nobles Artes de Madrid (1826 - 1853)
}

\author{
José Enrique García Melero*
}

\begin{tabular}{|c|c|}
\hline RESUMEN: & SUMMARY: \\
\hline $\begin{array}{r}\text { Estudio de los proyectos de cárceles } \\
\text { realizados por los aspirantes a los } \\
\text { títulos de arquitecto y de maestro de } \\
\text { obras en la Real Academia de Bellas } \\
\text { Artes de San Fernando de Madrid } \\
\text { entre los años } 1814-1844 . \text { Se } \\
\text { analiza en particular el modelo de } \\
\text { planta, que semeja un palacio } \\
\text { fortificado. También se estudian en } \\
\text { general los elementos } \\
\text { arquitectónicos de todos los } \\
\text { proyectos: la posible ubicación de } \\
\text { las cárceles proyectadas en } \\
\text { determinadas ciudades españolas, } \\
\text { el empleo de los órdenes } \\
\text { arquitectónicos, los patios, las } \\
\text { celdas, el tribunal de justicia, la } \\
\text { capilla, los talleres y los materiales a } \\
\text { emplear. Se finaliza con un estudio } \\
\text { sobre estos aspirantes a los títulos } \\
\text { de arquitecto y de maestro de obras: } \\
\text { sus lugares de origen, formación y } \\
\text { obras ya realizadas, y las diferencias } \\
\text { existentes entre ambos. }\end{array}$ & $\begin{array}{l}\text { A study on the projects of prisons } \\
\text { performed by the architect } \\
\text { and mater builders' applicants } \\
\text { in the Royal Academy of Fine } \\
\text { Arts of Madrid between the years } \\
1814 \text { and } 1844 \text {. } \\
\text { It is particularly analysed the floor } \\
\text { model, which seems a fortified } \\
\text { palace. It is also studied the } \\
\text { different architectonic elements } \\
\text { of the projects: the possible } \\
\text { locations of the prisons projected } \\
\text { in different Spanish cities, } \\
\text { the use of the architectonic orders, } \\
\text { the court yards, the cells, } \\
\text { the court of justice, the chapel and } \\
\text { the materials used. Finally, } \\
\text { the places of origin, training and } \\
\text { works performed by the different } \\
\text { applicants are studied, and } \\
\text { the differences among } \\
\text { them are highlighted. }\end{array}$ \\
\hline
\end{tabular}

En el artículo «El panóptico de Bentham en los proyectos de la Academia (1814-1844)»1, analicé aquellos diseños presentados como prueba de pensado en esta Real Academia por aspirantes a los títulos de arquitecto y de maestro de obras, que seguían de una forma más o menos cer-

* Profesor titular. Departamento de $\mathrm{H}^{\mathrm{a}}$ del Arte de la UNED.

1 GARCIA MELERO, José Enrique: "El panóptico de Bentham en los proyectos de la Academia

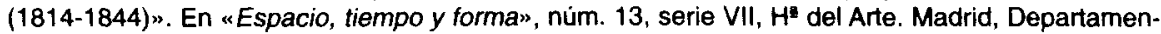
to de $\mathrm{H}^{\mathrm{a}}$ de Arte de la Facultad de Geografía e Historia de la UNED, 2000, pp. 293-328. Siguió a mi artículo titulado "Las cárceles españolas de la llustración y su censura en la Academia (1777. 1808)", publicado en esta misma revista, núm. 8 de la serie VII. Madrid, 1995, pp. 241-272. 
cana, repetitiva o recreativa el modelo entonces novedoso, que Bentham había proporcionado hacia 1790. Habia partido en gran medida del proyecto hospitalario de 1774 de Antoine Petit, médico y profesor de anatomía y cirugía de la Universidad de París, para el Hôtel-Dieu. Pero junto a estos dibujos, en los que casi todo es óptica, se conservan otros en el Gabinete de Estampas de la Real Academia de Bellas Artes de San Fernando2, que no promovieron tal propuesta, sino otra quizá más sencilla y conservadora, que mostraba la cárcel cual un palacio fortificado aún con algunas características específicas, a veces a modo de cuartel.

Entre 1826 y 1853 , fechas del primero y del último proyectos localizados en la Academia, que se corresponden con los informes facultativos guardados en su Archivo, no hubo una unidad formal sobre la tipología de la cárcel sino una diversidad de modelos y hasta de submodelos. Tal variedad es debida en primer lugar al tiempo transcurrido entre ellos, veintisiete años, lo cual originó, como resulta obvio, una cierta evolución de tales paradigmas y hasta de la misma forma de entenderlos y de enfrentarse con ellos. También hay que tener en cuenta que la introducción de los ejemplos en España debió ser, tal y como siempre solia ocurrir, algo lenta, aunque entonces lo fuese bastante menos que en otras épocas, pues hubo una cierta diacronía, en parte lógica, entre su invención y su divulgación en nuestro país por medio de publicaciones. Pero, además, los distintos modos de entender el presidio, tal y como se percibe en estos diseños, están motivados por la formación dispar de los pretendientes a los diversos grados de la arquitectura, otorgados por este centro de las Bellas Artes, y de sus mismos maestros, con quienes aprendieron la teoría y ejercieron la práctica mínima requerida para poder acceder a tales exámenes. También hay una notable diferencia entre los proyectos presentados por los aspirantes al título de arquitecto y los diseños más realistas de los pretendientes al de maestro de obras, puesto que cada una de estas dos categorias profesionales debian acomodarse a determinados principios reguladores de sus respectivos grados.

En este artículo se pretende generalizar, tras de referirme antes concisamente al modelo de cárcel a modo de palacio fortificado, sobre algunos de los elementos, que definen la tipología en la época del

2 Quiero aquí agradecer de nuevo las facilidades halladas en el Gabinete de Estampas y Dibujos de la Academia madrileña: a Isabel Azcárate Luxán y a Silvia Arbaiza, así como a su director mi maestro Antonio Bonet Correa. En el Archivo a Esperanza Navarrete. Del mismo modo a mi discípula Rosario Santamaría Almolda por su ayuda en la localización de los diseños. 
clasicismo romántico o del romanticismo clasicista en los proyectos de la Academia madrileña. Así, se analizarán con la mayor brevedad posible y en función de estos planos aspectos tales como la ubicación de la cárcel en la ciudad, que los aspirantes a estos títulos deseaban dar a sus proyectos, tal y como se exigia en ese centro de las Nobles Artes. Además, hay que considerar sus fachadas, se analizará el uso de los órdenes arquitectónicos en tales edificios, la disposición de los patios, de las celdas, de la capilla o iglesia, de los talleres y de la sala de justicia, así como se atenderá al empleo de los materiales recomendados. Finalmente me referiré de alguna forma a los hombres, que hicieron estos proyectos irrealizados, pero con posibilidad de haberse convertido en realidad, pues fueron pensados para ubicarse en determinadas ciudades y hasta, en ocasiones, en lugares muy concretos. Así, su grado de idealidad, o hasta de utopía, es en algo un tanto relativa.

\section{Modelos de plantas de cárceles en los proyectos de la Academia}

Los modelos novedosos empleados entonces fueron principalmente tres, cuya invención tuvo lugar en unas fechas ilustradas más o menos próximas en el tiempo: la influencia de la prisión de Ackerghem en Gante de figura poligonal con crujías radiales, construida entre 1772 y 1775 por Malfaison y Kluchman; el panóptico de Bentham y el modelo de John Haviland de la cárcel del Este en Cherry Hill cerca de Filadelfia según el diseño de 1825. A ellos habría que añadir la alternativa proporcionada por Durand en 1791, al partir de los diseños de Ledoux para Aix-en-Provence (1783-1785) y en calidad de modificación racionalista de su condición parlante tan elocuentemente terrible. Pero es también necesario referirse a una línea tradicional de correccional o cárcel, ya "clásica" y en uso, que enlaza con la prisión de Corte de Madrid de Juan Gómez de Mora de planta rectangular con torres en las esquinas, a la cual en ocasiones se superpuso entonces, o se citaba de una forma más o menos manifiesta o tan sólo referencial, el diseño de Durand.

Este abanico de posibilidades de modelos para una tipología obviamente está también en función del mismo año de realización de los dibujos por cada aspirante a los grados académicos de la arquitectura. Así, resulta significativo que en el proyecto (lám. 1), fechado en el año 1826, del vasco natural de la villa de Durango, Francisco Maria Aguirre, se empleara una planta al modo de la prisión de Gante: semioctogonal, de la que resultaba un hexágono irregular con un lado mayor muy alargado, 


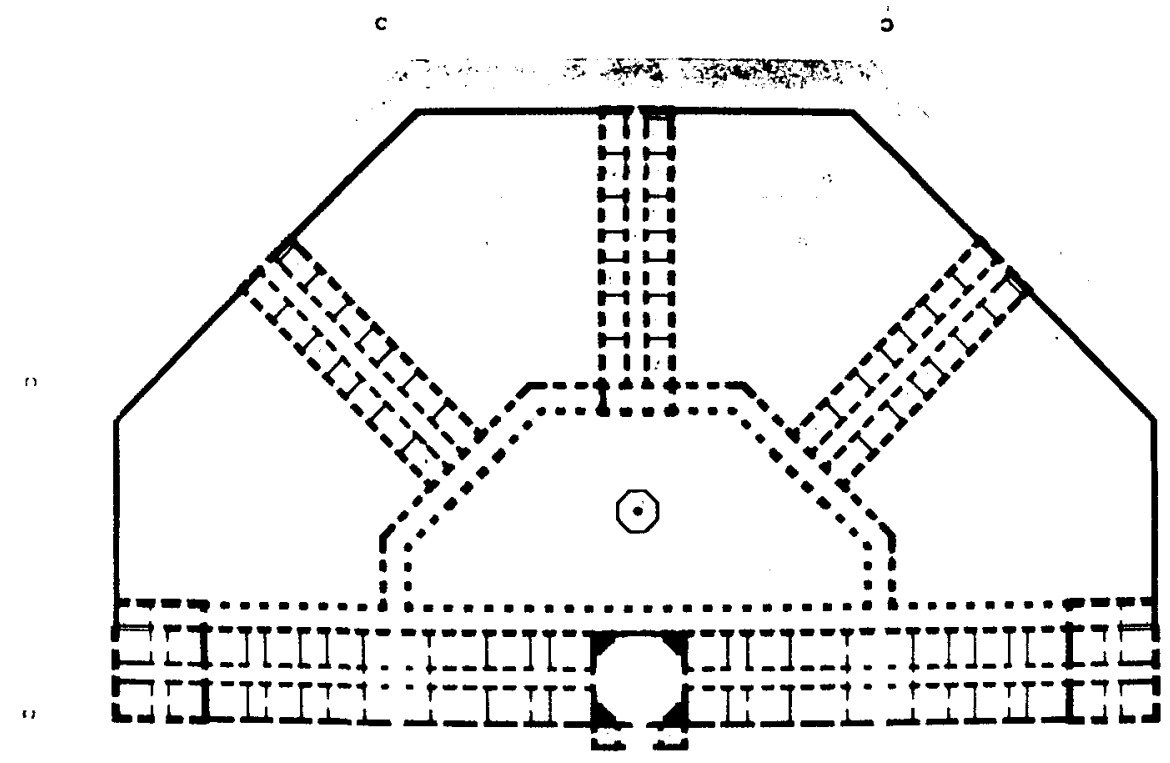

Lám. 1 Planta de la casa de corrección proyectada por el vizcaíno Francisco María de Aguirre en 1826. Discípulo de Isidro Velázquez, Manuel Ángel de Chavarri y Juan Antonio Cuervo, había trabajado con el segundo en el Espolón y el teatro de Vitoria.

trazando tres crujias radiales. El pretendiente destacó tal influjo en su memoria justificativa y lo debió hacer porque lo consideraba un ejemplo novedoso en la España de su época 3.

El modelo de la cárcel de Filadelfia fue seguido, entre otros, por el madrileño José María de Mariategui en su proyecto con destino a cárcel correccional de 1830, tal y como también declaró en el informe. Su planta, que tiene la forma de un paralelogramo rectangular con tres pisos y cuatro grandes patios porticados, obedece a la idea de clasificación de los presos según el sexo y el delito cometido; pero, asimismo, se halla en función de la importancia que se concede a los talleres como espacio singular y necesario 4 .

La influencia del modelo del inglés Bentham es, sin duda y tal y como indicamos en el artículo publicado en esta revista del año 2000, la más

3 Informe de 1826 de Francisco María de Aguirre en AASF: leg. 68-6/4. Diseños en AASF: Planos: A941 a A-943.

4 Informe de José María de Mariategui en AASF: log. 9-4/2. 
perceptible en todos estos proyectos. Sin embargo, fue modificada por medio de variantes o submodelos, que, aunque emplearan las líneas maestras referenciales diseñadas por el jurisconsulto inglés, proporcionaban ciertas novedades a un nivel doble general y también particular. Así, frente a la cárcel panóptica más ortodoxa de plan central circular u octogonal y hasta, algunas veces, polilobular, suele inscribirse dicho panóptico dentro de otra figura de planta, sobre todo, cuadrada o rectangular. Otra variedad viene dada por el empleo del semicírculo o semipanóptico, que en ocasiones es doble y aparece unido por otros cuerpos cuadrados o rectángulares, dedicados a servicios generales, para diferenciar los lugares que correspondian a los hombres de los destinados a las mujeres.

La proyección de otros espacios de planta distinta, normalmente rectangular y cuadrada, con respecto al panóptico, que, como norma, queda inscrito en su interior, suele obedecer a la necesidad de disponer de una serie de dependencias de carácter general dentro de la cárcel. Si éste asume su natural función de lugar de retención del preso, situándose en su contorno las celdas, aquél se emplea para residencia de los guardianes, para ubicar la sala de audiencia o juzgado y sus correspondientes oficinas y archivos, a veces para los talleres de trabajo de los reos, para la misma capilla en ocasiones... Viene a ser, además, un cuerpo regulador del conịunto, que une al tiempo que separa, y hasta de desahogo del mismo.

\subsection{Las cárceles como palacios fortificados}

Así pues, y no obstante al éxito alcanzado por un modelo de presidio influido por el panóptico de Bertham y más tarde por el celular en la época del Romanticismo histórico, muchos de los proyectos ideados por estos aspirantes a los títulos o grados académicos se hallan dentro de una línea en uso, que quizá se podría denominar tradicional y hasta, tal vez, clásica. Se acomodan a una planta, por lo general, rectangular o cuadrada, cuyas crujías están distribuidas en torno a un patio interior o a varios. Su origen se halla en el palacio, ahora fortificado, y también hasta en los mismos cuarteles. Aquella tipología palaciega, como prototipo, aporta en la mayoría de los casos una fuente de inspiración muy importante tanto en planta como en fachada, que incide, asimismo, en otras muchas. No en vano es una peculiar forma de habitat ennoblecido e idealmente representativo, que parte de la vivienda misma.

De aquí que la incidencia del palacio sobre la cárcel no sea algo tan extraño en un momento, durante el cual se estaba configurando de una manera a la par racional y funcional una tipología arquitectónica -que no 
dudo en calificar de tan romántica, aunque tal afirmación parezca contradictoria y hasta un tanto paradójica- y una serie de modelos propios. La conciencia de tipología carcelaria, tal y como hoy la entendemos, se configuraba entonces metódicamente a partir de unas nociones calificables de básicas codificadas en gran medida por Alberti, pues Vitruvio la "olvidó» por su condición miserable o la obvió. El palacio, un prototipo o primer tipo, del cual surgieron otros varios, es una construcción adaptable o acomodable, como a veces el mismo templo, a otras funciones distintas, aunque siempre, y poco a poco, fuera adquiriendo como tal ciertas peculiaridades en algo distintas, que se adaptaban formalmente a cada época.

En España parecía que aún pesaba mucho la influencia de la Cárcel de Corte, después Ministerio de Asuntos Exteriores, de Juan Gómez de Mora con su planta rectangular escurialense dispuesta en torno a dos patios y con su fachada principal enmarcada por dos torres, que se rematan por medio de chapiteles. No resulta extraño que el propio Juan de Villanueva, quien tanto gustó de dar al neoclasicismo un cierto aire castizo citando a Herrera, dibujara, aún siendo todavía casi un niño, la fachada de esta Cárcel de la Corte, que era un edificio considerado entonces cual totalmente clásico por su configuración. Años más tarde, en su informe sobre los estudios en la Academia de 1792 el autor de los diseños del Museo del Prado alabó a Juan Gómez de Mora. Lo calificó de ser uno de los mejores arquitectos españoles y añoraba su actividad como promotor de modelos clásicos y alejados de toda exuberancia barroca.

Ya varios años antes que Juan de Villanueva, en 1768, Elías Martínez habia realizado un proyecto para una cárcel de Corte con Chancillería destinada a una urbe populosa, que sigue esta trayectoria de Gómez de Mora5. Así, su planta rectangular se distribuye por medio de dos patios, y su fachada es bastante similar a esa Cárcel de Corte, tal y como se puede comprobar por el diseño de su proyecto.

Más sencilla es la fachada de una cárcel pública, diseñada por José Agustín Larramendi ya de $1790^{6}$ (lám. 2). Si Elías Martínez se manifiesta con nitidez como un barroco clasicista, éste se muestra ya totalmente neoclásico por la depuración de las líneas y de los ornatos. De dos pisos se cubre con tejado a dos aguas. Un pórtico de cuatro columnas de orden toscano se centra simétricamente en el edificio a modo de templete clási$\mathrm{co}$, que se corresponde con un segundo pórtico a cada lado de tres arcos

5 MARTÍNEZ, Elias: "Cárcel para una Corte, Chancillería, Ciudad o pueblo populoso". 20 de noviembre de 1768. Proyecto en AASF: Planos A-925-930 (8 planos).

6 LARRAMENDI, José Agustín: “Cárcel püblica”. 1790. Proyecto en AASF: Plano: A-934 (fachada). 


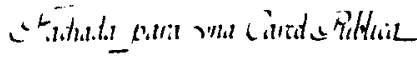
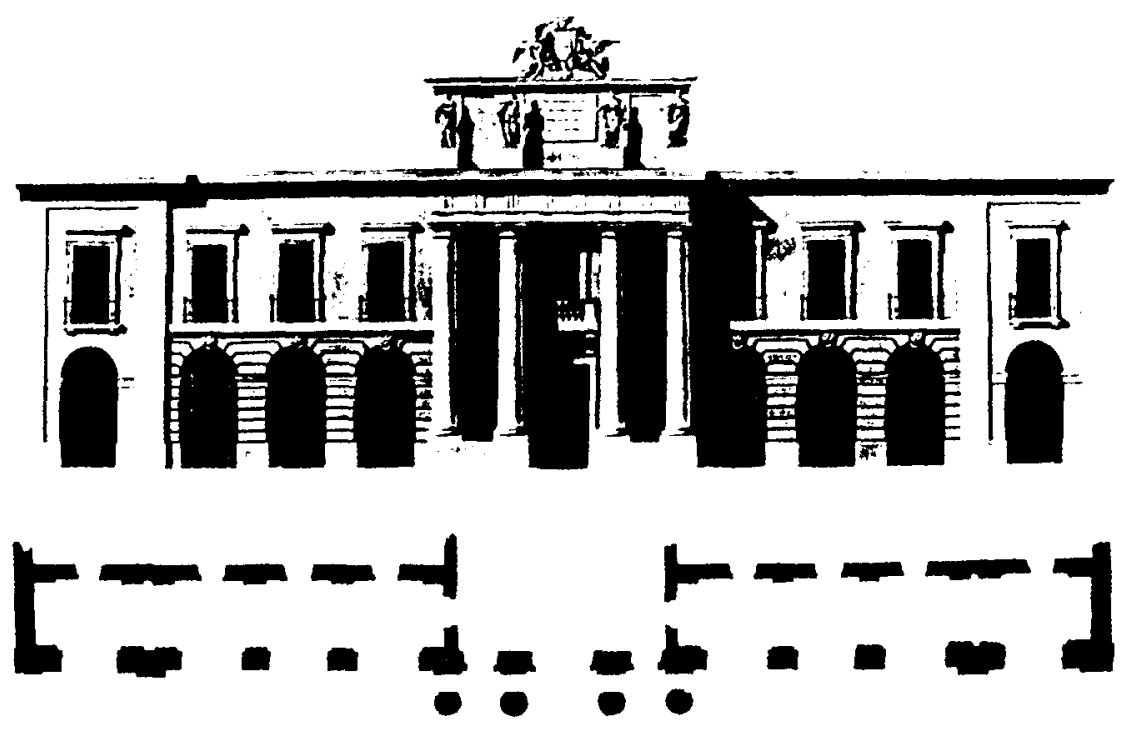

Lám. 2 Fachada para una cárcel pública. Proyecto de José Agustín Larramendi. 1790. Diseño en AASF: Planos: A-934.

almohadillado, que recorre la longitud de la fachada principal. Ya entonces parecía confirmarse la idea de que la cárcel debía hacer poco uso de los órdenes, y que únicamente debían embellecer las partes más nobles. Además, tan sólo se admitian los más sencillos, el dórico y el toscano, no habiendo lugar, por lo menos sobre el papel, para los otros, para el jónico, el corintio y el compuesto.

Por lo tanto, la planta rectangular, sin ninguna referencia al panóptico interior bien circular o semicircular, fue bastante empleada en sus diseños por muchos de estos pretendientes en sus proyectos para la obtención de tales títulos de arquitecto y de maestro de obra. Así, por ejemplo, se citarán aquí los dibujos de una cárcel para la ciudad de Jaén de Francisco José Carrillo de 1829. El futuro maestro de obras propuso un paralelogramo, un rectángulo muy alargado, que se distribuye por medio de tres patios con galerías interiores iguales, que cumplen cada uno de ellos una función distinta: el de la derecha para hombres, el de la izquierda para las mujeres y el del centro para desahogo y habitación del alcaide. Ubicaba dos capillas particulares en forma de $U$, que destinó a cada sexo?. Las celdas se situaban en torno a los lados de sendos patios laterales. 


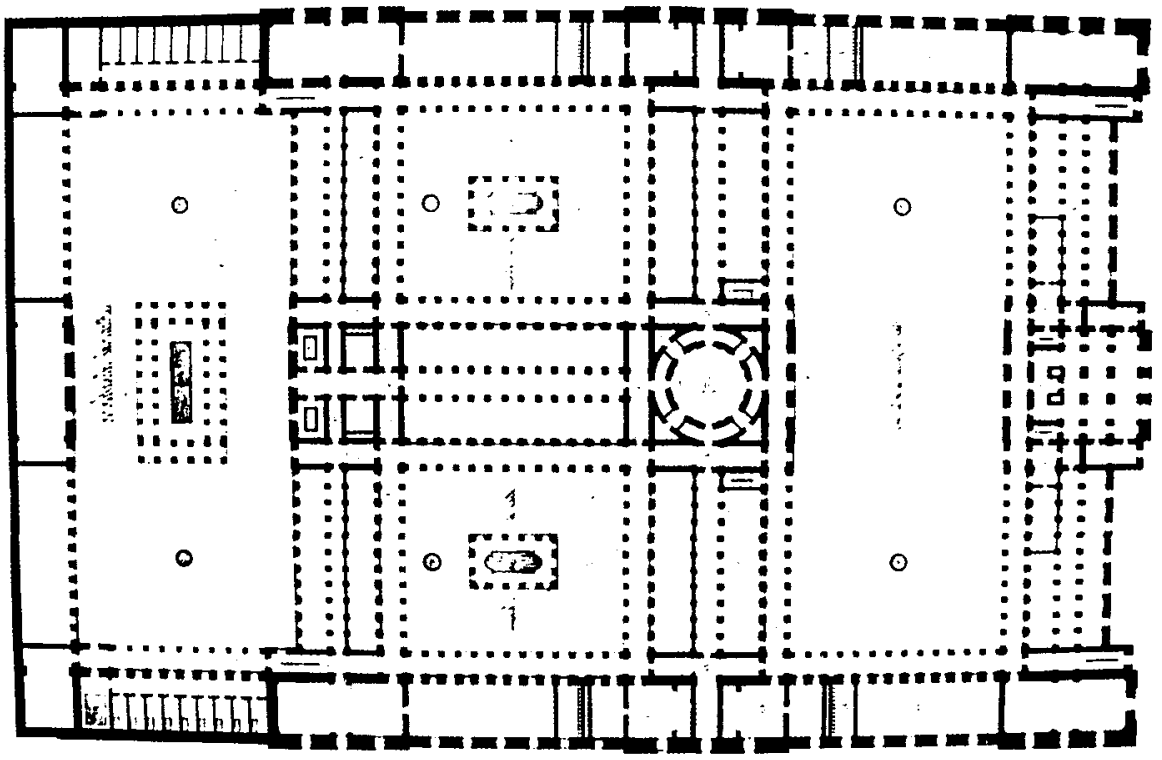

Lám. 3 Planta de cárcel correccional para Madrid. Proyecto de José María de Mariategui. 1830. AASF: Planos: A-948 - A-953. Leg. $9-4 / 2$.

Aunque se inspire en la cárcel de Filadelfia, el proyecto de cárcel correccional para Madrid (1830) de José María de Mariategui, quien buscaba alcanzar la conveniencia y la economía con su propuesta, se halla en esta misma línea de planta rectangular (lám. 3). Pero incluye cuatro patios porticados en su interior para lograr una mejor distribución y clasificación de los presos. El posterior sirve de desahogo con locales para almacenes, lavaderos...

La planta cuadrada con patio central rectangular con galería cubierta es empleada en la casa correccional para mujeres (1832) con destino a Vizcaya diseñado por el vizcaíno Mateo de Barrenechea (lám. 4). Viene a ser una especie de submodelo de estas cárceles de apariencia palaciega8. En sus diseños se percibe una simplicidad máxima y una sencillez

7 Informe de Francisco José Carrillo Serrano en AASF: leg. 16-3/2. Diseños del proyecto en el Gabinete de Dibujos de la ASF: planos: A-945 (planta baja), A-946 (planta principal) y A-947 (fachada principal). En los legajos de estas pruebas se halla información personal de cada pretendiente: partidas de nacimiento, certificados de estudios y de prácticas...

8 Informe de Mateo de Barrenechea en AASF: leg. 16-6/2. Planos: A-963 (fachada y planta baja) y A964 (corte y planta principal). 

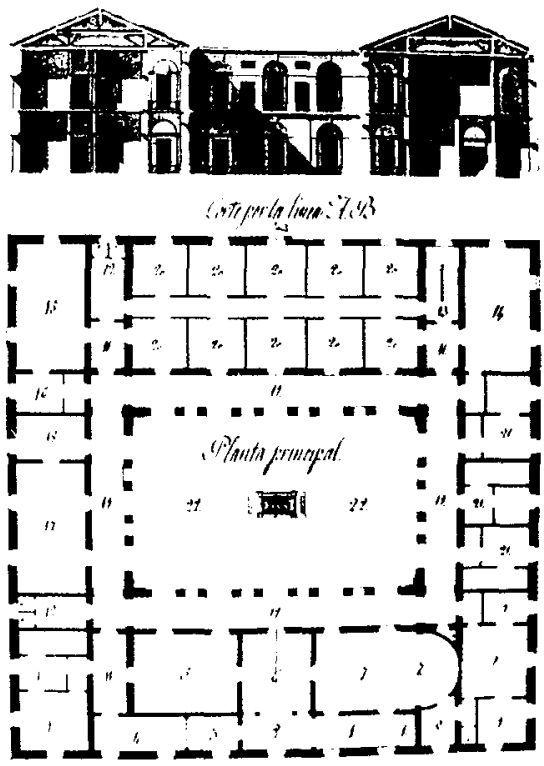

Lám. 4. Planta y sección de casa de corrección para mujeres. Proyecto de Mateo Barrenechea, natural de Durango (Vizcaya). 1832. Prueba para maestro de obras. AASF: Planos: A-963 y A-964. Leg. 16-6/2.
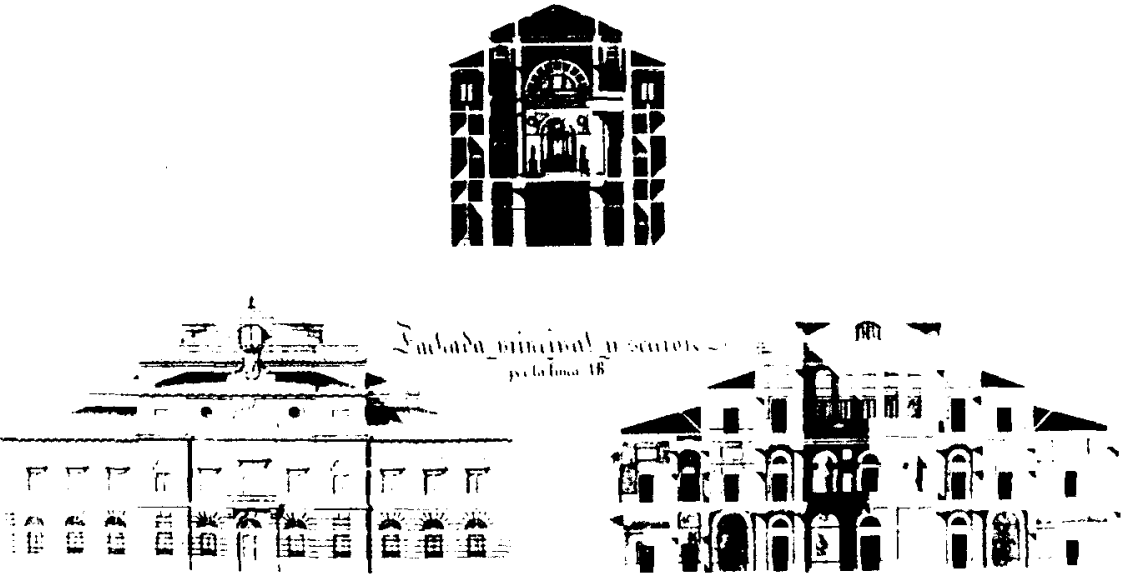

Lám. 5 Fachada principal y secciones de la cárcel de corona para reos de Estado de alta consideración. Proyecto del madrileño Manuel Mostaza. 1833. AASF: Planos: A-967. Leg. 10-2/2. 


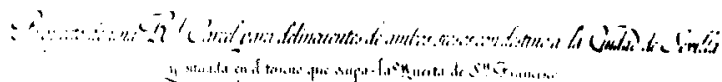

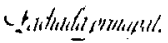
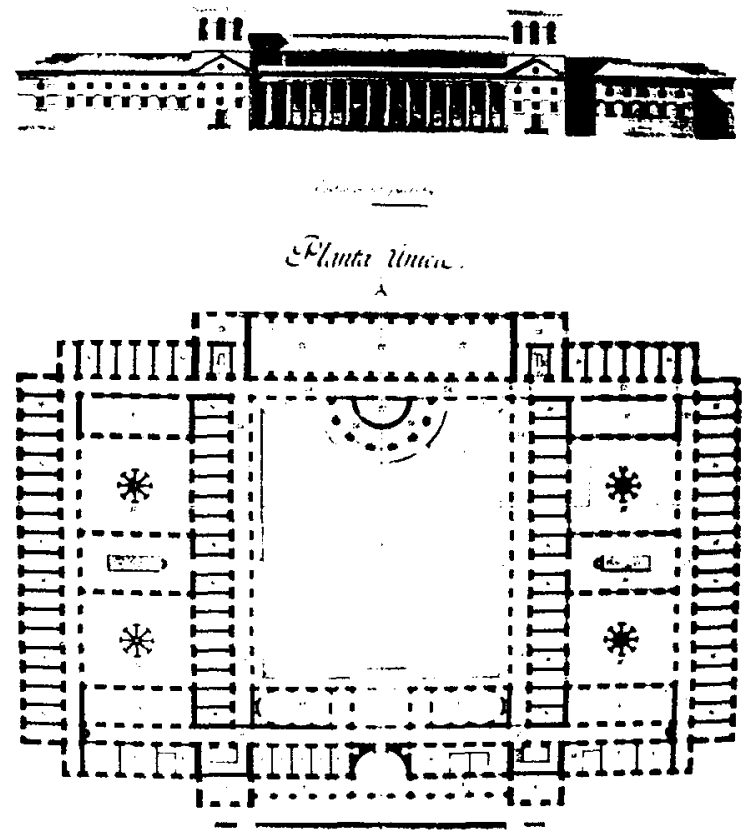

Lám. 6: Fachada principal y planta única de una Real

Cárcel para

delincuentes de ambos sexos con destino a la ciudad de Sevilla. Proyecto de José Zayas y Ribero. 1835. AASF: Planos A-973y A-974. Prueba para maestro de obras.

extremada de su fachada principal. Sin embargo, tales caracteristicas no se hallan en el pretensioso madrileño Manuel Mostaza (nacido el 10 de enero de 1805, aunque hijo de zamoranos) (lám. 5). Su proyecto para una cárcel de corona para reos de Estado de alta consideración, cuya planta cuadrada es muy similar a la de Barrenechea, presenta una ampulosidad

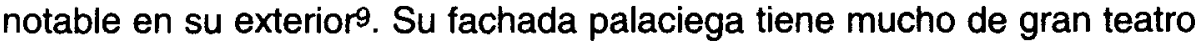
de Corte, es escenográfica, y aspira a ser representativa, como la función que trata de cumplir de albergar a reos de tan alto rango social. No hay una estricta correlación entre la forma del edificio y su finalidad carcelaria.

Los proyectos del sevillano José Zayas (lám. 6) ${ }^{10}$ y del catalán Miguel Umbert también se hallan dentro de esa línea de cárceles de planta rec-

9 Informe de 20 de febrero de 1833 del madrileño Manuel Mostaza en AASF: leg. 10-2/2. Planos: A966 (planta), A-967 (fachada principal) y A-968 (fachada laterall).

10 Informe del maestro de obras sevillano José Zayas y Ribero de 1835 en AASF: leg. 17-5/2. Planos A-973 (planta y fachada) y A-974 (segunda planta y cortes). 

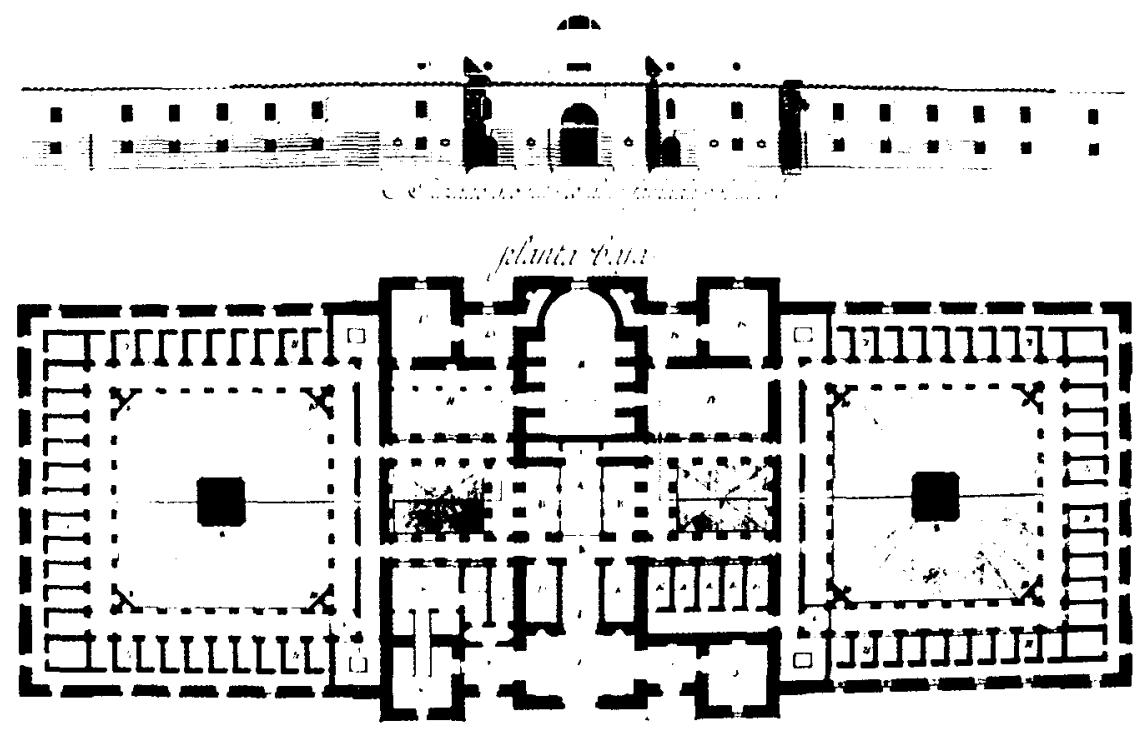

Lám. 7: Fachada principal y planta baja de una cárcel pública para la ciudad y puerto de Tarragona. Proyecto de José Morera Inglés. 1839. AASF: Planos A-987 - A-988. Leg. 18-1/2.

tangular con patios distribuidores, aunque el plan del primero resulta más complejo en algo que el del segundo. Aquél incluye en su planta rectangular con varios resaltes hasta cinco patios, siendo el central el más grande. Realiza una función tan representativa como de desahogo. Al fondo de la puerta de ingreso dispuso una capilla para que los presidiarios asistiesen a los oficios sacros desde las galerías. Los otros cuatro se disponen a cada lado de dos en dos y son para paseo de los presos. El otro pretendiente a maestro de obras, Umbert, natural de Mataró, es aún más sencillo en su propuesta que piensa de forma muy pragmática como cárcel civil de su ciudad natal.

El albañil José Morera, nacido hacia 1802, otro futuro maestro de obras, diseñó en 1839 una cárcel pública para Tarragona, cuya planta resulta rectangular al unirse tres módulos cuadrangulares, siendo los dos laterales de un tamaño uniforme y el central ligeramente más grande (lám. 7). El cuerpo central se destina a dirección y administración, e incluye junto a la fachada posterior la capilla11. En los dos laterales sitúa sen-

11 Informe de José Morera, natural de Tarragona, de 1839 en AASF: leg. 18-1/2. Diseños en Planos: A987 (fachada y planta) y A-988 (corte y fachada lateral). 
dos patios con fuentes y pilones. Sin embargo, su aportación más importante se halla en el empleo de materiales distintos de diferentes colores, como de "azulados", buscando la policromía del edificio.

Dentro de esta tendencia hay que citar la cárcel pública para la ciudad de Mallorca de Antonio Sureda, proyectada ya en 1846. Sin embargo, en este proyecto de planta cuadrada se percibe la influencia de los diseños realizados por Ledoux entre 1782 y 1785 para una prisión en Aix-en-Provence, que difundió con ciertas modificaciones internas Durand12. Resulta sencillo y reticulado. La influencia se aprecia, sobre todo, en la colocación en cada esquina de un cuerpo cuadrado en realce exterior de la línea de la fachada a modo de torres. Además, como esos modelos franceses, la cárcel de Sureda tiene cuatro pisos. Posee un sólo patio interior también cuadrado con fuente y galería circundante.

\section{Elementos arquitectónicos en los proyectos de cárceles de la Academia}

A modo de síntesis se tendrán en consideración aquellos aspectos que más definen al edificio de la cárcel. En primer lugar, los posibles modelos y submodelos de plantas de tal tipología arquitectónica, que sirvieron de inspiración a estos profesionales. A ellos ya me referí en el artículo anterior y en el epígrafe precedente sobre las cárceles, que semejan palacios fortificados. Pero también hay que ocuparse de su aspecto exterior y del uso de los órdenes arquitectónicos, asunto tan importante en toda fase clasicista o derivado por evolución, como este período fue, de ese clasicismo. La imagen exterior viene a ser la faz de todo edificio, la que la identifica en relación con su misma finalidad, diferenciándolo de otros distintos dedicados a cumplir otras funciones, y la anuncia. Este tema también lo abordé en ese artículo del año 2000 publicado en esta revista, motivo por el cual no insisto sobre él. Asimismo, hay elementos arquitectónicos, e incluso partes esenciales o no, que definen a la prisión: el patio, las celdas, la capilla, el tribunal de justicia, el taller... Forma, función y distribución caracterizan la cárcel. Por último, se aludirá con cierta brevedad al uso de los materiales. Se obvian el método constructivo, que es prácticamente común a casi toda arquitectura y acerca de la cual escribían, de una manera especial, los maestros de obras, y, asimismo, no se tratará aquí del presupuesto del coste de la obra. Este último aspecto

12 Informe de Juan Sureda y Ripoll, nacido el 14 de enero de 1810 en Mallorca, de 1846 en AASF: leg. 13-2/2. Planos: A-1001 (planta baja), A-1002 (planta principal), A-1002, A-1003 (fachada) y A-1004 (corte y alzado). 
constituye un complejo e interesante proceso económico muy importante, pero no específicamente artístico, que ha de considerar aspectos tales como los precios de los materiales, los salarios de los obreros y profesionales de la arquitectura, la relación entre el coste de este tipo de edificio y el de otras tipologías, la referencia comparativa con los valores cotidianos de consumo del momento... Es un tema que, dada su relación con la economía y su historia, dejo para un momento posterior a éste.

Pero junto a la tipología de la cárcel hay otro asunto muy importante que considerar, aunque se realice por medio de un simple esbozo: el humano, que aquí voluntariamente pospongo a los análisis formalistas e iconográficos; pero que no quiero olvidar. La obra de arte siempre está en relación con el hombre, a quien nunca hay que obviar para que la historia artística tenga un auténtico sentido. Es "obra» suya y su finalidad es deleitarlo y servirlo siempre. En el caso concreto de la arquitectura se halla en función de la naturaleza, de la que el edificio constituye un elemento de defensa de sus agresiones; pero que, como producto suyo, siempre tiende a imitarla. Dentro de este epígrafe dedicado al hombre, considerándolo a la vez como individuo y como colectivo, se analizarán las distintas procedencias y la formación de estos profesionales de la arquitectura, así como sus experiencias previas en la práctica. Prescindo de hablar sobre los distintos exámenes por los que pasaban estos aspirantes a los grados de la arquitectura, porque ya lo hice en otras publicaciones.

\subsection{Ubicación de las cárceles proyectadas}

Los proyectos de estos futuros arquitectos, maestros arquitectos y maestros de obras, quienes después diseñaron la arquitectura de la España de la época, tan empobrecida, revolucionaria y belicosa, la del romanticismo histórico, no son tan utópicos como se podría pensar al tratarse de una arquitectura de papel y tinta china orlada con imprescindibles sombras sepias. Sus autores pensaban que la mayoria de ellos podrian realizarse algún día en el lugar elegido para ello, que solía ser su localidad de procedencia. Una cosa es la utopía y otra bien distinta la idealidad, que algunos de ellos proporcionaron a sus diseños debido a que intentaban alcanzar un cierto grado de perfección dentro del sistema a la vez clasicista y funcional, entonces reinante en el instituto, al cual había que agradar. Además, el sistema docente de la Academia los obligaba a ello, pues debían diseñar el proyecto para ubicarlo en un lugar determinado, en una urbe concreta, con los materiales propios del país y los costes constructivos de la ciudad. El sistema era muy racional, por lo tanto, y siempre metódico, y se pretendía alcanzar una finalidad realista, aunque con cierto idealismo. 
Algunos de estos proyectistas habían meditado mucho la tipología elegida como prueba de pensado. Querian que su idea se cumpliera, que se hiciera realidad algún día. Sabían de las necesidades arquitectónicas de sus lugares respectivos de residencia y a ellas se acomodaban. De aquí se deduce que algunos de ellos se concedieran la ilusión a si mismos, a veces tal vez cierta, de que, una vez conseguido el título deseado, lograrían construir la idea a base de piedra, ladrillo, mampostería y madera, tras de utilizar el grafómetro, marcar los límites y figura en la tierra, y cimentar. Por ello no resulta extraño que en los informes facultativos, que comentaban los diseños de estos proyectos de cárceles, se indicara la situación siempre lastimosa de los presidios de la ciudad, en la que hipotéticamente se realizaría. Por lo tanto, había algunas lamentaciones, en las que siempre apoyaban ideológicamente, pero como si fueran esos mismos cimientos, su cárcel de papel.

Así actuaron catalanes, vascos, andaluces, castellanos y hasta los mismos madrileños, menos apegados a su tierra porque muchos de ellos no eran naturales, o no procedian familiarmente, de ella y resultaba complejo idear nada concreto en sitio tan competitivo y grandielocuente, como la Corte era. Es posible que, si todos estos proyectos se hubieran realizado, la España romántica habría conocido uno de los mejores sistemas penitenciarios de la Europa de la época. Pero, aunque no puedo confirmar la afirmación, pienso que no fue así, ni mucho menos, pues se quedaron en simples, pero maravillosos, diseños sobre el papel. Los tonos sepias se apoderaron de su inmaculada blancura y los diseños se han ensombrecido, adquiriendo humedad y hasta cierto moho, que la historia siempre produce, con el paso del tiempo. Un país empobrecido y bastante retrasado, que había conocido la Guerra de la Independencia casi en el mismo umbral del cambio de siglo, que había desamortizado para crear solares descongestionando la ciudad y quedarse con fincas, a las que daba otros destinos diferentes, al tiempo que lo hacía para proporcionar riqueza a la burguesía, en la cual apoyarse políticamente, y que, por último, estaba en guerra civil continua con el fantasma carlista, no podía permitirse tales licencias constructivas tan costosas. Además, tampoco lo pudo hacer en su mejor época, la de la España imperial, momento de la mayor miseria del sistema penitenciario español. La cárcel, como uno de los edificios donde más se manifiesta toda la limitación del hombre, debía ocultarse lo más posible. Venía a ser una micro ciudad en medio de la urbe.

El primer principio era su ubicación con respecto a la ciudad. Vitruvio, muchas veces tan enigmático, tan sólo dijo que debía construirse junto al 
foro. La situación céntrica de la misma impediria las fugas de los presos, pues, así, los ciudadanos se convertían involuntariamente en auténticos guardianes. Sin embargo, la insalubridad de los presidios, como consecuencia del hacinamiento y de la falta de ventilación, ocasionó tantas enfermedades a la ciudad, donde se hallaba ocupando generalmente el sitio privilegiado de la plaza mayor, que los proyectistas trataron de alejarla lo más posible de ella. Por este motivo se pensaban ocupando los barrios más distantes del centro y hasta extramuros de la urbe. Ahora se pretendía la salubridad y la ventilación para estos edificios, porque desde finales de la llustración la medicina había logrado hacerse oír y la arquitectura no se deleitaba en sí misma, ya no era tan autista, sino que comenzaba a hacer caso a otras disciplinas. La pretendida funcionalidad arquitectónica era servidora de las necesidades científicas, porque el edificio debía cumplir plenamente su finalidad, su función, de la forma más adecuada posible.

La novedad, pues, era alejar la cárcel de los lugares más céntricos de la urbe por motivos higiénicos, tal y como se hacía con los hospitales y se había hecho con los cementerios en España desde Benito Bails, y estos profesionales lo entendieron así. La mayoria de los proyectos se inician justificando metódicamente la ubicación de sus edificios. Ello lo justificaban en mayor medida los aspirantes más modernos que los más alejados en el tiempo. Pero unos fueron mucho más expresivos que los otros. Así, por ejemplo, un maestro de obras, el cartagenero Juan Ibáñez, avecindado en Murcia, a quien no hemos aludido antes por carecer de sus diseños, aunque se disponga de su informe, ubicó su pensamiento arquitectónico de 1827 para un ayuntamiento y cárcel pública en la llamada plaza real de Murcia, en el mismo sitio ocupado por la antigua casa consistorial en mal estado y de "poco gusto" tanto por su ornato como por la inadecuada distribución interior, careciendo, además, de la capacidad y de las comodidades convenientes. Sin embargo, hay que hacer notar que Ibáñez proyectaba un ayuntamiento con casa de detención, no un correccional específico13. De aquí que le situara en un lugar tan céntrico de la ciudad.

Francisco Carrillo pensó su cárcel para la ciudad de Jaén, su urbe natal, porque en su opinión la existente se hallaba en mal estado de conservación14. El madrileño José María Mariatégui, discípulo de Juan Antonio Cuervo y de Juan Inclán Valdés, ubicó, obviamente, el proyecto de correccional de 1830 en Madrid; pero sin indicar el motivo por el cual la des-

13 Juan Ibáñez, AASF: leg. 8-2/2. Era discípulo de Francisco Bolarín.

14 Carrillo, AASF: leg. 16-3/2. 
tinaba a la Corte 15. Juan Soler lo hizo para Barcelona e indicó antes que las cárceles en esta ciudad eran muy poco abundantes 16 . Propuso como posible construcción un extremo o a extramuros de la urbe, en pasaje aislado o separado de los demás para procurar ventilación. Deseaba ubicarla en concreto en la llamada Huerta de San Pablo, y entre el poniente y el mediodía. Mateo de Barrenechea ideó en 1832 su casa de corrección para mujeres para la provincia de Vizcaya, pero sin indicar en qué ciudad la localizaba 17 . Seguramente pensaría en Durango, su localidad natal. Cipriano Loitia, nacido en el 26 de septiembre de 1805, aún fue menos preciso, pues simplemente indicó que era un proyecto para una capital de provincia de doce mil habitantes 18. Es muy posible que pensase en Bilbao, su ciudad. El madrileño Manuel Mostaza tampoco localizó su cárcel de 1833 para reos de Estado de alta consideración en ningún sitio específico; mas quizá le ocurriera como a Loitia y tuviese en la mente la imagen de su Madrid19. Jimeno y Casanova tampoco ubicó su cárcel o casa de detención en un espacio concreto, indicando tan sólo que era para una capital de provincia20.

Otros profesionales fueron mucho más explícitos que éstos, tal y como es el caso, por ejemplo, de José Zayas, quien situó su cárcel real, dibujada en 1835, en el terreno ocupado por la llamada Huerta de San Francisco de Sevilla, su ciudad natal21. Además fue el único que concibió esta tipología como un colegio de educación, "donde el alcaide fuese su rector y sus satélites catedráticos de varias ciencias y artes". Aprovechó la ocasión para censurar las dos cárceles civiles sevillanas por ser mezquinas, irregulares y malsanas.

Por su parte Miguel Umbert, hijo, nieto y hasta biznieto de maestro de obras, también situó su proyecto de 1835 en su urbe de nacimiento, Mataró en la provincia de Barcelona, en la «industriosa» Cataluña22. Aludió a la importancia de esta localidad y criticó la cárcel ruin existente, carente de muchas oficinas principales e insalubre. Aunque se realizaron varios proyectos para edificar una nueva, no se había construido aún. Ubicaba

15 José Maria de Mariategui, 1830. AASF: leg. 9-4/2. Planos: A-948-A-953.

16 Juan Soler y Mestres, 1830. AASF: leg. 9-2/2. Planos: A-954-A-958

17 Mateo de Barrenechea, 1832. AASF: leg. 16-6/2. Planos: A-963-A-964.

18 Cipriano de Loitia de Gasmuri, 1832. AASF: leg. 16-6/2. Planos: A-962.

19 Manuel Mostaza, 1833. AASF: leg. 10-2/2. Planos: A-966-A-968.

20 Juan José Jimeno y Casanova, 1833. A.ASF: leg. 10-2/2. Planos: A-969-A-972.

21 José Zayas y Ribero, 1835. AASF: leg. 17-5/2. Planos: A-973-A- 974.

22 Miguel Umbert, 1835. AASF: leg. 17-6/2. Planos: A-978-A-A-979. 
su plan en la calle Bonaire, porque proporcionaba la ventaja de poder abrir un foso en torno suyo, pudiéndolo llenar con el agua procedente de los molinos.

Otro catalán, el tarraconense José Morera Inglés, pensó su cárcel pública para la ciudad y puerto de Tarragona23. Por tal motivo aprovechó la ocasión para referirse ampliamente a la situación de esta urbe, cuya población habia experimentado tanto crecimiento, después de muchos siglos de decadencia. Aludió a la cárcel existente en la villa, que se hallaba en las ruinas del palacio de Cesar Augusto, del que quedaba tan sólo un simple torreón. Pero, sobre todo, se mostró especialmente preocupado por el empleo de los materiales de la tierra.

El proyecto de Joaquín Ramón de Echeveste Mendiburu de una cárcel para San Sebastián, que presentó en 1839 como un simple ensayo según su opinión a pesar de su gran minuciosidad, tiene mucho interés, tal y como he ido demostrando por sus alusiones continuas a lo largo de estas páginas24. Había ya trabajado para Ugartemendía, uno de los reedificadores de la ciudad, destruida durante la Guerra de la Independencia. Justificó con extensión suficiente la ubicación de la cárcel ideada en el arbolado de San Francisco cerca de la carretera de Madrid a Francia y junto a una playa próxima al Urrumea. Además, dejaba claro que ya en San Sebastián había "un local muy adecuado para el objeto" y tenía plaza de armas con guarnición de seguridad, explicación que obliga a pensar que no hacía el proyecto para ser construido, sino como ejercicio académico necesario de arquitectura.

Maximiliano Hijón lbarra situó su plan de cárcel celular en la ciudad de Logroño25. En 1846 había presentado dos proyectos distintos, pero complementarios entre sí, dentro de una concepción tradicional: este correccional y una casa ayuntamiento. Ubicó el edificio en la plaza de la Constitución, en el solar donde se hallaba entonces el ruinoso palacio del Obispo, que se quería derribar con objeto de levantar un nuevo ayuntamiento para esta ciudad, que contaba entonces con 5000 vecinos. Pensaba reformar la plaza, decorándola con una fuente monumental, que situaba en su mismo centro geométrico. Tal idea tenía cierto grado de pragmatismo, pues resulta posible que quisiera realizarla personalmente, o que tal vez pudiera llevarla a cabo una vez aprobado el correspondiente título de maestro arquitecto.

23 José Morera, 1839. AASF: leg. 18-1/2. Planos: A-987-A-988.

24 Joaquín Ramón de Echeveste, 1839. AASF: 11-1/2. Planos: A-983-A-986.

25 Maximiliano Hijón, 1846. AASF: leg. 13-5/2. Planos: A-992-A-993. 
Antonio de Sureda tan sólo se limitó a situar en 1846 su cárcel pública en la ciudad de Palma de Mallorca; mas sin indicar el sitio exacto de ubicación26. Al haber escrito antes con cierta extensión sobre Gago como modelo de arquitecto racionalista, y también interesado, a la hora de localizar su industriosa cárcel en Sevilla, sólo nos falta referirnos a Ángel Calleja Rábanos27, puesto que ni Juan Farelo Díaz ni Manuel Maffei Bozal, alumnos ya de la Escuela Especial de Arquitectura, proporcionan pista alguna sobre dónde situar sus correccionales. Sus informes muestran la obsesión historicista y por la resistencia de los materiales, tan propia del nuevo centro educativo, y a la Academia acudian simplemente a revalidar sus estudios, pues se había dispuesto no quitarla de un plumazo toda su función docente ya secular.

Calleja pensaba en 1847 que era imprescindible dar a la cárcel existente en la ciudad de Burgos otro destino distinto, porque ocupaba uno de los lugares más céntricos y principales de la urbe, hecho que se oponía a la idea ilustrada de construirla en el extrarradio. En efecto, estaba situada frente al nuevo teatro y en la entrada al paseo del Espolón, y junto al mismísimo puente de San Pablo. Creía que debía destinarse el antiguo edificio a servir de Aduana, puesto que se hallaba en uno de los sitios de mayor tránsito. No es extraño que después se derribase y que en su solar se ubicara pocos años después la diputación provincial. Sin embargo, no indicó en dónde debería levantarse su cárcel con audiencia. La antigua, la célebre de Carlos III, que se había convertido ya en Peso Real, fue derribada hacia 1858 y en su solar se construyó el Palacio Provincial. Dos arquitectos burgaleses lo realizaron: Luis Villanueva y, precisamente, Ángel Calleja..., aspirante al título de arquitecto con esta prueba de repente sobre una cárcel. Quien había ideado un presidio sobre el papel, derribaba otro a los pocos años de haberlo diseñado bajo su influencia, quizá uno de los más importantes erigidos durante la llustración española junto con el de Cádiz.

\subsection{El empleo de los órdenes arquitectónicos}

Casi todos estos proyectistas coincidieron también al afirmar que en tales edificios apenas debería hacerse uso de los órdenes clásicos, porque no los juzgaban adecuados a su finalidad. Sin duda, no resultaba un lugar apto para ello. No era posible la ostentación ni la recreación

26 Juan Sureda y Ripoll, 1846. AASF: 13-2/2. Planos: A-1001-A-1004.

27 Ángel Calleja, 1847. AASF: leg. 14-1/2. Planos: A-944. 
clásica en el sentido más fácil del término de quienes identificaron siempre tan sólo los clasicismos con el empleo de este elemento arquitectónico, aunque sea tan esencial en términos figurativos. Entonces tales tendencias los relacionaron con las estructuras desornamentadas, pero elocuentes hasta en la proyección misma de las luces y de las sombras. Una cárcel nunca puede mostrarse ostentosa, sino siempre funcional y bastante sombria para lograr los efectos figurativos y expresivos deseados. Si los ornatos sobraban, también era necesario prescindir de las columnas en calidad de decoración, sin otro sentido que la finalidad auténtica de elemento sustentante. La pilastra escondida dentro del robusto muro sólido de sillares y de ladrillos podía realizar tal función, sin "amanerar» la imagen del edificio, que debia siempre anunciar su destino y persuadir de la conveniencia de no delinquir ante el futuro castigo de aislamiento tan terrible. El empleo de los órdenes clásicos, lujosos siempre, servirían al espectador más de estética atracción curiosa que de temeroso rechazo hacia la finalidad misma de tales edificios.

Es de suponer el desagrado que a algunos de estos arquitectos quizá los produjera el no poder emplear, o usarlos muy poco, los órdenes, tan académicamente clasicistas y representativos de una intención estética, que no siempre de una mentalidad. De aquí que se pensara aplicarlos tan sólo en aquellos lugares del edificio, cuyo uso resultase siempre imprescindible según las normas de la tradición. Había que destacar de alguna forma los sitios considerados como más nobles. Es decir, parecía imprescindible poner columnas en los pórticos de entrada, alusión casi inevitable al clasicismo, en las capillas, en las audiencias y en los patios porticados, sobre todo en los de desahogo, lugares todos ellos tan representativos; pero la mayoría ubicados en el interior $y$ no en el elocuente exterior visible de la cárcel. La relación entre las ideas de Dios y de la justicia del hombre lo requerían así. También era necesario llegar a un cierto compromiso convencional en su uso, pues si la cárcel debía ser sencilla y austera, se pensaba que tal simplicidad únicamente la proporcionaban algunos determinados órdenes arquitectónicos en el caso de tener que emplearse necesariamente. El jónico, el corintio y el compuesto parecían demasiado ostentosos, delicados y, tal vez, hasta inadecuadamente femeninos para su destino, pues para algunos los órdenes tenian una cierta connotación sexual. Sólo habia lugar para la aplicación del dórico y del toscano, tan primitivos, tan recios, tan viriles y sin ornatos.

El soñador catalán Juan Soler y Mestres, quien debía sentirse obligado a citar la arquitectura grecorromana, empleó los órdenes clásicos, 
como referencia explícita a la Antigüedad, en espacios muy concretos de su cárcel para Barcelona, cuyo proyecto es la síntesis de un pasado, presentado como antagónico y hasta conflictivo, con la modernidad28. Así, en el centro geométrico del patio dispuso un rectangular templete dórico, que, según indicó, debía ser, al estilo del teatro Marcelo, con 12 columnas y cubierta apuntada a dos aguas. Pero, además, en la fachada principal situó un atrio con dos columnas al estilo de Phaestrum con su escalinata saliente de cinco gradas.

Francisco María Aguirre en la segunda fachada de su proyecto también dispuso un pórtico dórico de dos columnas, al modo de templo «in antis", con arquitrabe y frontón, pero sin friso. Situó dos hornacinas flanqueando ambos lados para colocar en ellas esculturas alusivas a la función del edificio29. Sin embargo, el Marqués de Socorro en su idea de casa correccional proyectó dos columnas entre otras tantas pilastras, no en la entrada a modo de templete, sino en la planta principal para destacar la nobleza de la sala del tribunal.

Resulta curioso que Manuel Mostaza en su ostentoso proyecto de cárcel de corona para reos de Estado de 1833 no pensase en diseñar un pórtico en la fachada, sino que simplemente almohadillara el piso bajo y colocase una puerta de entrada en sencillo arco. Sin embargo, el futuro maestro de obras José Zayas en sus diseños de cárcel para Sevilla dispuso un estrecho y largo pórtico corrido de doce columnas dóricas entre dos torres, para dar énfasis a la fachada principal. Por su parte Miguel Umbert ideó otro pequeño pórtico de cuatro columnas dóricas entre sendas garitas sobre las que se apoya el arquitrabe y el frontón triangular. Miguel Geliner también pensó un pórtico con columnas dóricas dispuestas de dos en dos...

Así, nunca se abusó del empleo de los órdenes arquitectónicos en los proyectos académicos sobre esta tipología, pues no resultaba oportuno para su destino. La conveniencia era precisamente una de las reglas vitruvianas más significativas. De este modo, las cárceles forman parte de una arquitectura bastante funcionalista, que no participa ya de un clasicismo fácil y estereotipado por el uso de la columna. Su elocuencia reside en la falta de ornatos, en la escasez y pequeñez de los huecos, la lisura y robustez de sus muros, el uso como norma de un sólo ingreso... 


\subsection{Los patios}

Uno de los elementos más importantes de la cárcel, tal y como ocurre en casi toda tipología arquitectónica, es el empleo peculiar y a veces dispar de los patios. Constituye la fuente principal de luz para el interior, ante la escasez de vanos en las fachadas. Además, asume otras muchas funciones: distribuye las distintas dependencias, unas veces uniéndolas entre sí y otras separándolas; suele ser sitio principal desde el que se vigila, sobre todo por medio de la torre del panóptico, que ocupa su centro; es lugar higiénico de esparcimiento y de recreo de los presos; sirve en algunas ocasiones de desahogo; en su centro se sitúa la fuente y una gran pila para el aseo, si no está ocupado por ese panóptico; muchas veces en él se ubica una capilla abierta para que los presos puedan asistir bien desde sus mismas celdas, bien desde el pórtico a los oficios religiosos... De esta forma el patio se constituye en parte clave y funcional para la vida y la salubridad en el interior de la cárcel.

Se puede decir que hay tres clases distintas de patios en la tipología carcelaria: el patio de desahogo, que se relaciona con la parte directiva y administrativa del presidio; el patio para recreo e higiene de los presos; y el patio del panóptico, cuyo centro está ocupado por la torre de vigilancia, desde la que se divisa el interior de las celdas dispuestas en torno suyo. Se trata de diferentes modalidades y furiciones, que, en más de una ocasión, suele asumir tan sólo un patio en determinados edificios.

Como norma ha de tener galerías porticadas para que los presos puedan pasear por él los días fríos y lluviosos, o los soleados en extremo de las jornadas estivales. Su centro o lo ocupa una higiénica fuente de piedra o la omnipresente torre del panóptico. En ocasiones cobija en el piso bajo los talleres, donde los presos trabajan para redimirse y ser productivos. No suele contener jardín o arbolado, salvo en muy contadas ocasiones, para no distraer al preso, quien ha de meditar sobre el delito cometido y arrepentirse de él. En esto se diferencia claramente del jardín hospitalario, que muchas veces asume, además de una función higiénica, otra finalidad botánica al cultivarse plantas medicinales en él para proveer la botica.

En los proyectos objeto de comentario el número de patios está casi siempre en función de la planta del edificio. Así, en algunas propuestas son numerosos y en otras tan sólo se piensa en uno, pero fundamental para la distribución, ventilación, iluminación y recreo. Así ocurre por ejemplo en los diseños de Mateo Barrenechea de una casa de corrección para mujeres, o en la cárcel de corona de Manuel Mostaza, o en la propuesta 
para Sevilla por José Zayas, o en la de Mataró de Miguel Umbert, o, por último, en la Mallorca diseñada por Antonio Sureda. En realidad, el número de patios depende de la ambición del proyecto propuesto, de su extensión, por cada aspirante a los grados de la arquitectura de la Academia madrileña.

Lo lógico, si se pensaba en la recomendada norma jurídica de la distribución de los presos en el interior de la cárcel según el sexo, la edad, si ya habían sido juzgados o no y por el tipo de delito cometido, era que existieran varios patios para poder tenerla en consideración. En las cárceles mixtas había dos: uno para hombres a la derecha y el otro a la izquierda para las mujeres, tal y como ocurría en los hospitales. Pero a veces se situaba en medio otro patio de desahogo en la parte general dedicada a la administración y dirección del penal. Asi ocurre, por ejemplo, en el proyecto de cárcel para la ciudad de Jaén diseñado en 1829 por Francisco José Carrillo. En el realizado por José Morera diez años después para Tarragona hay dos cuadrados laterales con galerias porticadas, en cuyas esquinas ubica las letrinas. Esta disposición de separación se cumple, asimismo, en aquellas otras cárceles con semipanópticos en los extremos, que dedican cada uno a un sexo distinto, tal y como es el caso de la idea del Marqués de Socorro de 1831 o de Juan José Jimeno y Casanova de 1833, aunque ambos proyectos incluyen más patios: el primero hasta cinco y el segundo otros tantos, aunque los dos centrales sean pequeños.

El vasco Joaquín Ramón Echeveste en su diseños de cárcel de 1839 para la ciudad de San Sebastián llegó a incluir, ni más ni menos, que hasta doce patios; pero todos ellos los diseñó excepcionalmente con árboles. Quizá pensara en su pais tan lluvioso como frondoso. Este proyecto de presidio fue el único que entonces se propuso como un edificio «ecológico". Los presos también debían participar de alguna forma de los placeres de la naturaleza en sus recreos. El gran número de patios propuesto en su "pensamiento" arquitectónico es la consecuencia obligada por la complejidad de la misma figura de su planta, donde coinciden cuatro figuras geométricas: un gran rectángulo general, derivado de la concurrencia de un gran cuadrado central, que contiene en el interior el círculo del panóptico, con otros dos rectángulos estrechos. Pero al mismo tiempo una crujía divide longitudinalmente el edificio sirviendo de eje de simetría, mientras que otras dos medías crujías lo hacen de modo transversal. Como consecuencia del encuentro de tantas figuras geométricas y de tales ejes edificados se derivan: cuatro patios rectángulares iguales en los dos rectángulos extremos; otros cuatro triangulares con uno de sus lados 


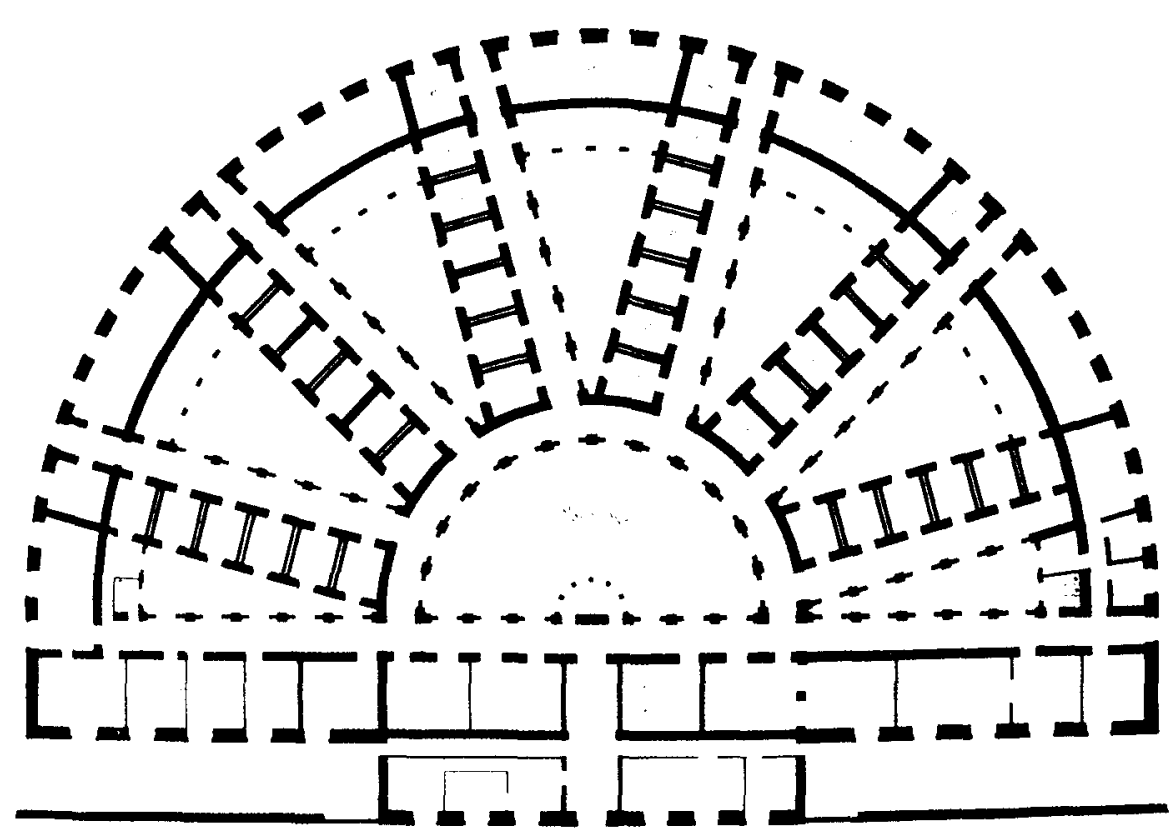

Lám. 8 Planta de una cárcel de partido. Sistema radial y celular. Proyecto del madrileño Juan Farelo y Diaz. 1852. Examen final de carrera según el reglamento de la Escuela Especial de Arquitectura de acuerdo con la Real Orden del 25 de agosto de 1847. AASF: Planos: A-1007 - A-1009. Leg. 14-3/2.

curvos del encuentro del cuadrado central con el círculo del panóptico y, por último, cuatro más en el interior de éste derivados del cruce radial de cuatro pequeñas crujías.

Sin embargo, el proyecto, que incluye mayor número de patios, es el realizado por Maximiliano Hijón en 1846, también como consecuencia de la compleja, no magnitud extrema, figura de su planta, que obedece a la idea de clasificación de los presos. Su cárcel celular llega a contener hasta dieciocho, de los que tan sólo uno ocupa el centro de su trilobulado panóptico. En realidad, su idea era que cada uno de los diecisiete restantes, tan exiguos en sus espacios disponibles, se correspondiera a cada fila en altura de celdas, de tal manera que nunca coincidieran en ellos los presos, pues las horas de los recreos serian diferentes para cada uno de ellos. Se define, así, el concepto de la soledad absoluta del prisionero no sólo en su habitáculo habitual, sino también a la hora del esparcimiento al 
aire libre. Desde las celdas bajaban al patio por medio de una escalera de caracol. Se trata, pues, de una cárcel escueta, de alta seguridad, tal vez pensando para reos de peligrosidad cierta.

El sistema de cárcel de crujías radiales, derivadas del modelo de la Maison de Force en Gante, también proporciona numerosos patios al presidio, dependiendo del número de aquéllas. Ello se manifiesta en el proyecto de casa de corrección de Francisco $M^{a}$ Aguirre, cuya planta poligonal de seis lados, en realidad un semidecágono, incluye tres crujías de celdas que forman entre sí y con el lado mayor de servicios generales, cuatro patios distintos dedicados a otros tantos tipos de presos. Pero diseña otro de desahogo tras de esa crujía principal.

Algo similar ocurre con la idea de cárcel de partido de Juan Farelo Díaz, quien se mostró tan historicista en su informe facultativo, ya de 1852 (lám. 8). Su cárcel celular se halla más cerca de la influencia de la prisión de Gante que del panóptico de Bentham. Su planta semicircular está atravesada por seis crujías radiales que definen con la principal y de ingreso, siete patios para la clasificación de los presos, más uno semicircular interior de desahogo y con capilla. Todos ellos están porticados.

\subsection{Las celdas}

Contra lo que podría pensarse, en los informes facultativos de estos aspirantes, quienes serían gracias a estos proyectos pocas semanas después arquitectos y maestros de obras, apenas se alude a cómo debían ser las celdas, aunque constituyen una de las partes más representativas de la cárcel. Lo único que queda ya bastante claro en ellos es que los presos no se apiñarían en salas únicas como durante el siglo XVII y los inicios de la llustración, sino que ocuparian un habitáculo individual 0 , algunas pocas veces, de dos o tres presidiarios por cada una de ellas. Ello obedece a la idea de que los presos sólo se comunicarian entre sí, aunque siempre agrupados según el sistema de clasificación ya expuesto antes, en el taller, donde hacían el trabajo redentivo, y en el tiempo de recreo en el patio, pero no se relacionarían entre ellos en el encierro. Así, el sistema, al mismo tiempo y paradójicamente, trata de humanizar el espacio, que individualiza, pero deshumanizándolo de algún modo al procurar el aislamiento personal e impedir todo tipo de comunicación entre los reos durante la reclusión en las celdas. Se trata de que no se "contagien" la depravación moral los unos con los otros y que mediten aislados sobre el delito cometido, la pena recibida y los medios posibles de recuperación. 
El sistema de celdas quedó definido por Bentham en su propuesta, fruto del racionalismo ilustrado, que tanto éxito tuvo durante el Romanticismo histórico. Así, quienes de estos aspirantes le siguieron -que fueron bastantes, cual ya se ha demostrado-, las concibieron como él, enrejadas y abiertas al patio central, hacia donde se alza la torre del panóptico. $A$ veces hay detrás una puerta a las galerías. De este modo el alcaide o el vigilante de turno podría saber lo que cada preso hacía en su interior, sin ser visto. Debían pensar que eran observados continuamente y sentirse, así, incómodos para delinquir. El presidiario se convierte de esta forma día y noche en centro visual de un penoso espectáculo percibido desde el poder. Además, de esta forma estaba ventilado.

Las desigualdades sociales también llegaron a estos diseños de cárceles. Así, en varios de los proyectos se dedicaban determinados espacios especiales a las personas de consideración o alto rango. De esta manera, ya antes se vio que Manuel Mostaza habia diseñado toda una cárcel espectacular para reos de Estado, destinada a un número limitado de personajes 30 . En ella los presos ocupaban auténticos apartamentos, casi tal y como los concebimos en la actualidad. Junto a su habitación se hallaría la del criado, quien, al parecer, también debería penar los delitos cometidos por su señor, y hasta vestíbulos y salas. Un trozo de la crujía de la derecha con forma de salón corrido estaba dedicada a los ejercicios de los presos y a sala de reuniones sociales. Tenian hasta sala de billar y biblioteca, situada encima de los baños del piso bajo. Además, en la azotea se disponía en el plano de Mostaza una galería descubierta antepechada para que dispusieran no sólo de buenas vistas y distracción, sino del aire más puro.

Pero esta arquitectura sobre papel, trazada a base de tinta china y sepia, de Manuel Mostaza, con tantas pretensiones más propias de una sociedad estamental que de la revolución burguesa decimonónica, venía a ser una especie de utopía o diversión de proyectista con mucho de ensueño romántico más irrealizable que otras ideas menos grandiosas. Las demás cárceles podían retener a señores distinguidos, mas en pequeños espacios dedicados a tal finalidad. De este modo, otro soñador, Juan Soler y Mestre, concibió que las cuatro torres de su edificio dispondrían en la planta baja de cocinas y que las altas estarían ocupadas por los reos de Estado o personas de mucha distinción de ambos sexos 31 . También daba la posibilidad de dedicarlas a encierro de aquellos reos, que deberian hallarse incomunicados o separados.

30 Mostaza, AASF: leg. 10-2/2.

31 Soler, AASF: leg. 9-2/2. 
En algunas de las memorias facultativas de los proyectos de presidios con plantas convencionalmente más tradicionales, como las rectángulares y cuadradas, se indicaba que las celdas debian carecer de humedad y estar ventiladas por las luces de los patios. Para lograrlo José Morera las elevó sobre el pavimento exterior32. También este maestro de obras quería que fueran incombustibles, motivo por el que prefería cubrirlas por medio de bóvedas de cañón.

El riojano Maximiliano Hijón concedió bastante extensión en su informe a la descripción de las celdas, que incluía en su proyecto de cárcel celular para la ciudad de Logroño33. Las consideraba el espacio principal del edificio. Ocupaban la parte trilobular de la planta. Indicó que su extensión sería de 15 pies de longitud, 12 de anchura media y 13 de altura. Situó altas ventanas para renovar el aire; pero desde ellas el preso no podía ver el exterior por su gran altura. Cada celda dispondría de un aseo, estufa y salidas particulares al patio individual por medio de una escalera de caracol.

\subsection{El tribunal de justicia}

La mayoría de estos proyectos de cárceles incluían el tribunal de justicia entre sus muros y algunas de ellas hasta habitaciones para los jueces. Sin embargo, en algunos informes facultativos de los aspirantes no se hace referencia a tal sala. Adjuntas a él se hallan casi siempre el archivo y la escribanía, que servían de imprescindible complemento administrativo, estando precedida por una antesala. Dentro del edificio ocupaba un lugar destacado, pues generalmente era ubicado junto a la fachada delantera, duplicando a veces el tamaño de sus huecos con relación a los demás vanos. Presidia, así, la planta principal y su presencia era perceptible desde el exterior. Además, la existencia de un tribunal importante por el número de juicios atendidos en las grandes urbes hacía que los arquitectos concedieran a esa cárcel unos aires más nobles y hasta palaciegos, conteniendo más celdas para detenidos en espera de juicio que presidiarios de delitos ya reconocidos. De aquí que poco a poco se fuera diferenciando la audiencia como una tipología específica relacionada, pero también independiente de la cárcel, tal y como consta en los libros de asuntos a sortear para las pruebas de estos aspirantes a los grados de la arquitectura. 
Sin embargo, no se refieren de forma expresiva a cómo debia ser esta dependencia tan significativa de la cárcel. Simplemente se limitaron, como norma casi general, a indicar dónde se ubicaría dentro del conjunto. No obstante, era una de las pocas partes del edificio que, debido a la misma nobleza de su función, podía hacer uso de los órdenes clásicos de la arquitectura junto con la iglesia y el pórtico. Era centro, por lo tanto, de la zona general, directiva y administrativa de la cárcel, situándose distante de las celdas y cerca de la entrada principal. Algunos correccionales tenían otro ingreso posterior para los presos, reservándose aquél para el personal, aunque la jurisprudencia recomendase que tan sólo hubiera una puerta a fin de evitar las fugas.

\subsection{La capilla}

Todo edificio público de importancia debía contar entonces con una capilla al ser España un Reino católico en su misma esencia existencial. Si en los hospitales asume la función de uno de los espacios arquitectónicos más representativos junto con el colegio de cirugía, y por servir de consuelo al paciente en la enfermedad, en la cárcel desempeñaba un papel educativo de gran importancia, además del propio religioso. La reeducación del preso se hacía, sobre todo, por medio del trabajo y por la formación moral en el cristianismo, su dogma natural. Tan sólo algunos informes aludían a la inclusión de determinadas aulas para la enseñanza, no exclusivamente religiosa, dentro del plano de la planta de los presidios.

Por lo tanto, resulta muy raro hallar un diseño de cárcel sin que se incluya una capilla en estos proyectos académicos siempre en una situación especialmente privilegiada. A veces se disponen varias para cubrir las necesidades espirituales de los diversos presos distribuidos en la prisión según el sistema de clasificación sexual o por el tipo de delito cometido. El lugar de su ubicación, sin embargo, suele ser bastante dispar y depende en gran medida del modelo de planta empleado. En el panóptico se sitúa, por lo tanto, en un sitio clave: en medio del patio formando parte de la torre óptica, cuya función principal es la vigilancia.

Asi lo hizo Bentham en su propuesta de modelo tan original; pero estos discípulos españoles madrileños, catalanes, vascos, andaluces y aragoneses, que se examinaron en la Academia, concedieron casi siempre a dicha torre del panóptico más un carácter religioso que de inspección, pues en ella colocaron principalmente la capilla para que todos los presos pudieran asistir a los oficios religiosos desde las mismas celdas sin tener que trasladarlos. De esta forma, el ojo invisible de Dios sustituia al del 
hombre y se hacia omnipresente, mucho más impresionante que el humano. En sus informes no solian aludir a la condición de la torre como, sobre todo, sitio de vigilancia de los presos, sino de la ubicación de la capilla en este sitio concreto.

En los proyectos que incluían la propuesta de dos semipanópticos -como los del Marqués de Socorro de 1831 y la de Juan José Jimeno de 1833- se diseñaron sendas capillas semicirculares, dedicadas la una a la sección de hombres, ubicada a la derecha, y a la de mujeres, en la izquierda. Aquél proponía que tales capillas, a las que se unía una habitación cuadrada a su lado posterior recto dedicado a sacristía, una vez celebrados los oficios religiosos, pudieran cerrarse funcionalmente por medio de celosias dispuestas entre los intercolumnios. Ocurre del mismo modo en los demás proyectos inspirados directamente en el panóptico, como, por ejemplo, el de Echeveste, ya de 1839. Más explícito fue Juan Soler al indicar que en medio del patio central disponía un templete dórico, al estilo del teatro Marcelo, con doce columnas y cubierta apuntada a dos aguas. En su interior coloca un crucifijo con las gradas y la mesa correspondiente para celebrar la misa34. Maximiliano Hijón proyectó en este lugar de la torre un templete dórico de madera y situó encima la habitación del alcaide. Así, era congruente con el plan, tan racionalista, del jurista inglés.

Se puede deducir del estudio de estas capillas que sus plantas eran bastante dispares: las hay semicirculares, circulares, octogonales, en forma de U... Quizá se pueda afirmar aqui que predominan las de plan central. Suelen ser bastante sencillas, tal y como correspondía a este tipo de edificio, donde todo ornato y lujo sobra. Además, si diferentes son sus plantas, la ubicación de tales capillas también resulta muy diversa. Ya hemos visto que los proyectos, que siguen más de cerca el modelo de Bentham, la sitúan en la torre de vigilancia del patio central; pero en otros su localización resulta más diversa. Unos la diseñan en la planta del proyecto tras el vestíbulo principal; otros en correspondencia con la fachada más noble y hasta en la planta principal. Los hay quienes la dispusieron en la parte posterior y quienes la concedieron el lugar central del edificio... Tampoco es extraño que ocuparan una parte del patio en cárceles que no seguian con fidelidad el sistema panóptico, para que los reos asistieran a misa desde las galerias.

En este último sentido hay que destacar a José Zayas y también a Miguel Umbert. El primero de ellos, en su cárcel para Sevilla, la situó al fondo del patio central, próxima a la fachada posterior, en un semiperíptero 
dórico con cellas. De esta forma los presos podían asistir a misa a resguardo de toda inclemencia climática desde las galerías porticadas del piso bajo y desde las ventanas del superior. Miguel Umbert ubicó la capilla con su sacristía en el testero del patio, elevada sobre el terrado, para que también los presidiarios pudieran oír los oficios religiosos desde las galerías, pero estando el sacerdote siempre custodiado para evitar motines. Este sistema parece tener cierto paralelismo de alguna forma con el modelo de Bentham, aunque no lo siguieran con fidelidad en la planta dada al edificio.

En relación con otras ubicaciones más dispares, tanto con respecto a las fachadas delantera y posterior, y el centro del edificio, se dieron las circunstancias siguientes: Aguirre ubicó la capilla próxima a la entrada de la principal en la gran crujía alargada y tras del vestíbulo. La dio una planta octogonal. Sin embargo, Francisco José Carrillo diseñó sendas capillas, una para las mujeres y la otra dedicada a los hombres, en forma de U en la planta baja. José María de Mariategui la dibujó circular con tribunas para los presos de alguna consideración. La situó en uno de los dos centros del edificio en medio de la crujía, que separa el patio para presos de delitos leves de los otros dos, quedando unida a ellas la crujía central. Barrenechea en su cárcel para mujeres dedicó a capilla, también de planta en $U$, una de las partes más nobles del edificio, la planta baja a la fachada principal, ubicación que también concedió Manuel Mostaza.

\subsection{Los talleres}

La jurisprudencia de la época, basándose en los imprescindibles juristas de la llustración, como, por ejemplo, Bentham, Cunningham, Burton y otros, sostenía que el preso debía estar continuamente ocupado; pero, sobre todo, por medio del trabajo productivo. Pero ello debía ser siempre compatible con la imprescindible seguridad del edificio. De aquí que las cárceles tuvieran que contar con talleres para que los presidiarios se ocuparan en un oficio. Siempre productivo a un doble nivel: como modo de ocupación y sistema de formación del reo para su reintegración social a la hora de salir del presidio; pero también para su sustento y el mantenimiento de la misma cárcel. De aqui se comprende que algunas de ellas, además de estos talleres y de sitios dedicados a almacenes de materias primas, contuvieran hasta lugares, a modo de tiendas, para la venta de los productos elaborados por los presos.

Esta idea se puede considerar como muy ilustrada. Había que educar al pueblo no sólo para mejorar su calidad de vida, sino también, y sobre 
todo, para lograr la mayor calidad y el aumento de la producción general del país. Lo cual repercutía, sobre todo, en la economía de unos pocos privilegiados, poseedores de materias primas, de talleres de producción y de sistema de difusión y venta. Las utopias de la llustración solian ser casi siempre muy realistas frente a lo que comúnmente se piensa, aunque se las conceda esa denominación, y tenían, casi como norma, una doble finalidad: la aparente y la auténtica. Lo eran, sí; pero más en la forma expositiva que en el fondo auténtico. La utopía ilustrada expositivamente resulta un tanto teatral, escenográfica.

Nuestros proyectistas debían ceñirse con cierta fidelidad, así pues, a las normas de la jurisprudencia de la época. De este modo lo hicieron la inmensa mayoría de los examinandos a la hora de diseñar sus proyectos, en los que el taller ocupa un sitio muchas veces privilegiado. Su importancia era tal que un granadino, aspirante al título de arquitecto ya en la época romántica del año 1847, Favio Gago Muñoz, diseñó una de estas utopias con un sentido en el fondo tan utilitario siempre ${ }^{35}$. El modelo puede servirnos de ejemplo para mejor entender la importancia de los talleres dentro de la cárcel, aunque ya haya sido comentado en otro artículo.

Gago, hijo de un capitán de los ejércitos nacionales, denominó a su proyecto presidio con fundición de cañones con destino a Sevilla. Afirmaba que su idea podría realizarse con la simple voluntad de los políticos administradores del país. Partía de un hecho muy concreto: de la existencia en esta ciudad del Guadalquivir de unas fundiciones de cañones, que no resultaban realmente rentables debido a la mala ubicación de la fábrica y a los grandes gastos ocasionados por los salarios de los obreros. Quería, así pues, procurar al gobierno muchos ahorros de sus caudales y, también, proporcionar una ocupación cierta a los presos de las cárceles sevillanas. De aquí que su presidio constara de dos partes uniformes y bien elocuentes: el panóptico y los talleres, que se ubicaban a ambos lados de este edificio. Gago quería economizar, pues los presos, como modo de redimir penas, apenas ocasionarían gastos algunos. Ello se conseguía también abaratando el coste de los transportes, pues la ubicaba en la proximidad del río para facilitar el embarque y conducción tanto de los materiales a los talleres como el de todos los arsenales de la artillería destinada a la marina. Para lograrlo un canal circundaba la totalidad de la cárcel, al tiempo que lo ponía en comunicación con el Guadalquivir.

El proyecto de Gago, tan utópicamente realista, viene a ser el resumen de la suma de intenciones perceptibles en los diseños de muchos de 
sus compañeros a lo largo del tiempo que nos ocupa, pues la rentabilidad del trabajo de los presos se halla en la práctica, explícito o de forma implícita, en varios de los informes facultativos de los demás. Se recordará aquí, por ejemplo, que Mariategui, amparado por la idea filantrópica de que el trabajo constituía un tema básico para la recuperación moral de los presos, pensaba que su cárcel correccional se dedicara a la manufacturas o labores de esparto, cáñamo y lanas, basándose para ello en las circunstancias, costumbres e industria de España36. Trataba de ocupar a los presos y hacerles ganar con tales labores su manutención y todos los gastos que tuvieran. De aquí se deduce la importancia que en su proyecto tienen tanto los talleres como los almacenes de productos brutos y para dar salida a los ya elaborados.

Gago concedió a los talleres casi más importancia que al mismo panóptico con sus celdas, mero sitio del "descanso" y del imprescindible sueño cotidiano para poder volver al trabajo, por lo menos intencionalmente; pero los demás aspirantes a los grados académicos de la arquitectura se ocuparon muy mucho de no descuidar su ubicación dentro de estos edificios. Los situaron, casi como norma general, en las plantas bajas, o debajo de las celdas de los panópticos o en los patios. Hay una relación entre los lugares de trabajo y del recreo, muchas veces contiguos, pues eran los únicos sitios, donde los presos podían relacionarse socialmente, ya que en las celdas debían hallarse casi siempre aislados. A veces los concedieron sitios específicos en una zona de la planta destinada a los talleres o en la general y administrativa del presidio. Sin embargo, ninguno menciona cómo debían ser estos talleres y qué forma tendrían. Se puede deducir que los espacios destinados a esta finalidad eran amplias salas rectángulares y abovedadas en todos aquellos proyectos pensados para que las cárceles fuesen incombustibles.

No escapo aquí, por último, a la tentación de hablar del trabajo de las mujeres en estos lugares de reclusión, pues, en ocasiones, se indica con toda claridad en los informes de los examinandos. Ello ocurre, sobre todo, en aquellos correccionales, que contenian presos de ambos sexos, silenciándose en la cárcel para mujeres, diseñada en 1832 por Mateo de Barrenechea37. En ellos se las otorgaba la siempre imprescindible misión de lavar la ropa de toda la cárcel. Para ello se disponían grandes lavaderos en sitios muy concretos, por lo general, situados en los patios femeninos o en su entorno, en relación de geométrica simetría con el mismo lugar

36 Mariategui, AASF: leg. 9-4/2.

37 Barrenechea, AASF: leg. 16-6/2. 
que los hombres se ocupaban en los talleres. La sociedad "romántica", que tanto ensalzaba poéticamente a la mujer como sujeto amoroso, de nuevo las otorgaba a ellas una función doméstica, igual que ocurriría, resulta pensable, en la vida familiar de sus domicilios.

\subsection{Los materiales}

La elección de materiales para levantar teóricamente y sobre el papel el edificio proyectado constituía, junto al cálculo económico de los costes de la obra y al método constructivo, un tema siempre imprescindible en estos proyectos. Los maestros de obras, sobre todo, desarrollaban extensamente el método de construcción. Además, la aplicación de los distintos materiales a este tipo de edificio estaba en función de una de las grandes obsesiones del momento: lograr que la cárcel fuera incombustible, lo cual también predisponía al empleo de estructuras abovedadas de diversos tipos y a prescindir de la madera lo más posible para impedir los incendios. Ello encarecía considerablemente la construcción. La misma obsesión obviamente tenían desde siempre quienes diseñaban proyectos de teatros en la España de la época.

Aunque tal utilización debía estar en función de los materiales propios del lugar geográfico, donde se proyectaba ubicar siempre hipotéticamente el edificio, la mayoria de los informes coinciden en ellos, y diferenciaban espacios arquitectónicos y sitios muy concretos para cada uno. No obstante, algunos de estos profesionales -sobre todo los maestros de obras porque debian ocuparse principalmente de este asunto- eran más elocuentes a la hora de escribir sobre el particular que los otros, a quienes parecía preocuparlos menos el tema de los materiales y se mostraban más obsesionados por la planta y distribución de los distintos espacios y elementos.

Los materiales más nobles se empleaban en los lugares más representativos de la cárcel: portadas, capilla, tribunal de justicia y patios de desahogo. Siempre se alude a las piedras blancas de Colmenar y Berroqueña, como las más prestigiosas por su calidad y belleza. Además, se usaba mampostería en los cimientos y ladrillo como material predominante en las zonas menos nobles, para los tabicados y distribución interior de las habitaciones... La sillería se aplicaría a la fachada principal. Rejas y canceles de hierro, y ventanas y puertas de madera según los países. Los patios se empedraban o enladrillaban. Se usaba la teja común para las cubiertas del tejado... 
Francisco María de Aguirre concedió bastante importancia al empleo adecuado de los materiales, cuyo acopio, indicaba, siempre debía preceder por lo menos en tres o cuatro meses al comienzo de las obras38. Estableció la mezcla entre la cal y la arena en proporción respectiva de $2 / 3$ y 1/3. Se refería a que había que emplear piedra blanca de Colmenar para enlosar el suelo de la capilla y losas delgadas de Berroqueña para los zaguanes y galerías. En las puertas de entrada y del interior, y en las ventanas aplicaria pino de Soria como el mejor de todos.

José Morera Inglés quizá fuese el más elocuente de todos ellos a la hora de referirse a los materiales, pues se extendió bastante sobre este tema. Parecía buscar una cierta policromía del edificio al indicar los colores y tonos de los mismos ${ }^{39}$. Así, proponía el empleo de todo tipo de "azulados, materiales que están en uso en la ciudad de Tarragona». También se refiera a la piedra labrada, pero lisa "de la llamada lisos de color», y de la denominada sabinosa de color amarillento rojiza.

Otro vasco, Echeveste, se extendió bastante a la hora de referirse a los materiales a emplear en su hipotética cárcel para San Sebastián40. Dejaba bien claro que pretendía aprovechar los propios de su tierra. Por ello eligió la madera de roble, que consideraba de excelente calidad en el país. La aplicaba para la realización de la armadura del salón de Audiencia, de las habitaciones particulares, de los suelos, de las partes interiores, del sofito del peristilo, de las cimbras, planchas, andamios... También destaca los sillares de piedra maciza, muy abundantes en la región. El ladrillo lo emplearía en los trabajos ligeros del interior por su calidad regular.

\section{El hombre: los proyectistas de la Academia}

El paso del tiempo muchas veces diferenció entre sí a estos proyectistas, aspirantes a los distintos grados de arquitectura de la Academia. Hay que tener en cuenta que entre el primer diseño estudiado y el último median algo más de un tercio de siglo. Así, la formación de unos y de otros resulta bastante dispar, en algo distinta. El instituto no era un "elefante congelado y cubierto por toneladas de hielo", tal y como se escribe a veces. Hubo una evolución cierta a veces más acelerada, a veces más desacelerada. La mayoría realizaron su formación dentro del sistema académico o en el admitido por la propia Academia en otros centros pro- 
vinciales afines reconocidos por ella o con un profesional arquitecto o académico de mérito salido de sus aulas. Pero los últimos pretendientes a los títulos de la arquitectura, cuyos proyectos han sido analizados antes, en lugar de examinarse como aquellos, convalidaron el título en este centro por medio de unos ejercicios muy parecidos, mas habiéndose ya formado en las aulas de la entonces recién fundada Escuela Superior de Arquitectura en Madrid, cuya apertura tantas esperanzas produjo. Ello proporciona una serie de notas diferentes bastante perceptibles, pues en ella se hicieron mucho más técnicos, a la par que paradójicamente historicistas, dados los nuevos planes de estudios. Así, se preocupaban por la resistencia de los materiales a un nivel matemático más novedoso y no tan sólo para indicar cuáles eran los más adecuados a su proyecto.

Tal vez haya que preguntarse aqui, en primer lugar, algo que es posible que no tenga una respuesta rotunda: ¿por qué motivo estos aspirantes a los grados académicos de la arquitectura eligieron voluntariamente como prueba de pensado el proyecto para una cárcel?. Si en la de repente el asunto lo elegía el aspirante entre una terna de temas salidos en suerte de un libro de asuntos, en esta inicial de invención no ocurria lo mismo. El futuro profesional de la arquitectura lo había seleccionado entre múltiples posibilidades. Quizá la misma respuesta esté en el propio ambiente de la arquitectura de la época.

Ya se ha visto en otro artículo cómo la cárcel había sido un edificio, junto a la casa consistorial, que había ocupado mucho a los arquitectos de la llustración. La España ilustrada se llenó de ayuntamientos; pero también de celdas en edificios de detención y en prisiones. Parecía obligatorio en un país llenó de mendigos y de delincuentes, de umanos muertas o desocupadas", que recorrian casi masivamente los distintos Reinos casi sin rumbo fijo, cometiendo delitos. El Conde de Campomanes se había preocupado mucho de la mendicidad en sus informes como Fiscal del Consejo de Castilla, tal y como demuestra la documentación existente en su archivo personal, conservado en una gran parte en la Fundación Universitaria Española; pero también le inquietaba la delincuencia que esta masa de desarropados producía. Además, estaba obsesionado por la educación popular en un oficio, necesaria para que España se hiciese productiva. Sus preocupaciones parecen reflejarse en estos mismos informes.

Pero, además, pienso que la cárcel era una de las tipologías entonces en boga por dos motivos: debido a la intención de los juristas ilustrados de humanizarla y por sus mismas posibilidades arquitectónicas tan novedosas. Howard había visitado las cárceles de Europa y comprobado sus deficiencias. Bentham habia ideado un modelo de edificio en su época re- 
volucionario. Los franceses, como Ledoux y Durand, también estaban preocupados con la mejor forma de construir un presidio según esa nueva normativa jurídica.

Por estos motivos no resulta extraño que los modestos Aguirre, Ibáñez, Carrillo, Soler, Solano, Barrenechea..., aún en lugares a veces bastante alejados de los principales focos de la arquitectura, se ocupasen de proyectar este tipo de edificios, tan necesarios y útiles según la mentalidad de la época, en sus lugares respectivos de residencia. Los modelos se habían multiplicado y se habían abierto novedosas posibilidades. Además, ya me he referido en otras ocasiones a la modernidad de una serie de tipologias arquitectónicas -- el teatro, la cárcel y el hospital --, que, sin olvidar el dibujo como lenguaje peculiar del artista y nexo entre las distintas artes, enlazaban por necesidad, quizá de una forma más científica, con las matemáticas y la física, la medicina, la jurisprudencia, la literatura... Los arquitectos comenzaban a sentirse, tal vez en algo, más útiles que antes y a abandonar toda su "genialidad casi divina", que posponian a la funcionalidad de sus proyectos.

\subsection{Los lugares de origen y formación}

En el cómputo general de la totalidad de proyectos existentes en la Academia se percibe un hecho curioso: predominan los aspirantes vascos, después de los madrileños y junto a los catalanes y andaluces. Parece ser que faltaban profesionales de la arquitectura en aquél país, tal vez por el incendio de San Sebastián durante la Guerra de la Independencia y la necesidad de reconstruirla; pero, además, los vascos, al parecer, gustaban de esta profesión artística tan prácticamente vivencial. Así, Salustiano Ardanaz, Francisco María de Aguirre, Mateo de Barrenechea, Cipriano de Loitia y Joaquín Ramón de Echeveste, quienes habían proyectado cárceles como prueba de pensado, eran de alli. Quizá también pudiera pensarse que hacía falta construir cárceles en Vascongadas, aunque queda constancia de que en San Sebastián no ocurría asi.

Hubo, obviamente, bastantes madrileños entre estos proyectistas de presidios, como José de Mariatégui, José Solano quien era Marqués de Socorro, Manuel Mostaza, Juan Farelo y Manuel Maffei. Eran discípulos de la Real Academia, donde se habian formado con algunos de los mismos profesores que los examinaban: con Custodio Teodoro Moreno, Juan Antonio Cuervo, Juan Miguel Inclán Valdés, Matías Laviña... Farelo41 y 


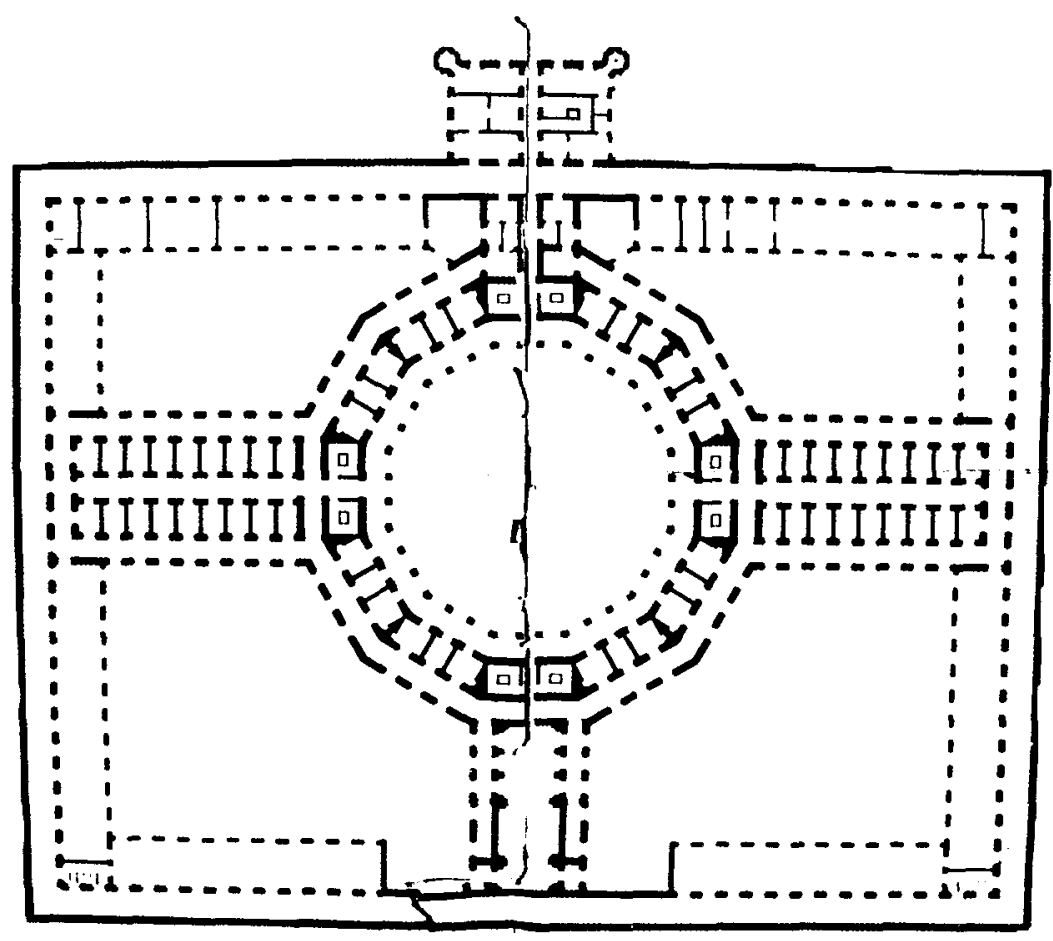

Lám. 9 Planta de un correccional panóptico. Proyecto del madrileño Manuel Maffei Bozal. 1853. Prueba de examen final de la Escuela Especial de Arquitectura. El asunto obedece al tema numerado con el 11 del libro de asuntos: correccional para 150 jóvenes detenidos. AASF: Planos: A- 1011-1015. Leg. 14-5/2.

Maffei (lám. 9) 42 habían estudiado ya en la Escuela Especial de Arquitectura, percibiéndose en sus diseños un cierto cambio en el sistema educativo.

Sin embargo, algunos de estos aspirantes procedian de la Escuela de la Lonja de Barcelona, donde se habían formado con el novedoso e innovador Antonio Celles, quien era académico de mérito de las Reales Academias de San Fernando y de San Carlos de Valencia. Este es el caso, por ejemplo, de Juan Soler y Mestres, asombroso por su proyecto de cárcel43. El zaragozano Juan José Jimeno y Casanova, después académico 
de mérito precisamente por su disertación sobre la mejor curva del auditorio de un teatro, también había estudiado con él, quien le certificó la práctica a su lado44. Asimismo, Miguel Geliner cursó en esa Escuela barcelonesa matemáticas con Celles y arquitectura con José Oriol45. Pero también se presentaron otros catalanes: Miguel Umbert Puig, natural de Mataró46, y José Morera Inglés, quien había nacido en Tarragona, formándose en la práctica de la albañilería y en la Sociedad Económica de Amigos del País47.

Hubo varios andaluces que diseñaron cárceles como prueba de pensado o de invención, que era la inicial para poder presentarse después a la de repente en los locales de la Academia y al correspondiente examen oral. Así, Francisco José Carrillo Serrano era natural de Jaén y también se había formado en la práctica de la albañilería con José de Martos antes de acudir a este instituto para acceder al título de maestro de obras 48 . José Zayas y Ribero habia nacido en Sevilla y había cursado sus estudios en el Real Colegio de San Telmo con Juan Bruneque de Velasco 49. Fabio Gago era granadino. Había estudiado en la Universidad Literaria de Granada entre los años 1835 y 1837, realizando las prácticas con el arquitecto de la Academia Baltasar Romero50. Zayas y Gago ubicaron sus respectivos proyectos de cárceles en Sevilla.

Pero, además, se presentaron a exámenes, con el proyecto de una cárcel como prueba de pensado, en este centro de las Bellas Artes un cartagenero, Juan Ibáñez 51 , un riojano, Maximiliano Hijón52, un mallorquín, Antonio de Sureda y Villalonga53 y un burgalés, Ángel Calleja Rábanos55. Este último e Hijón, sin embargo, habían estudiado ya en la Academia madrileña para completar su formación inicial. Del burgalés se sabe que después construiría el palacio provincial de Burgos, en el lugar ocupado precisamente por la antigua y famosa cárcel, en cuyo derribo, al parecer, intervino.

\footnotetext{
44 Jimeno, AASF: leg. 10-2/2.

45 Geliner, AASF; leg. 10-3/2bis.

46 Umbert, AASF: leg. 17-6/2.

47 Morera, AASF: 13-1/2.

48 Carrillo, AASF: leg. 16-3/2.

49 Zayas, AASF: leg. 17-5/2.

50 Gago, AASF: leg. 14-1/2bis.

51 Ibáñez, AASF: leg. 8-2/2.

52 Hijón, AASF: 13-5/2.

53 Sureda, AASF: leg. 13-2/2.

54 Calleja, AASF: 14-1/2.
} 


\subsection{Arquitectos y maestros de obras}

No se ha diferenciado a la hora de estudiar todos estos proyectos entre quienes se presentaron a exámenes para acceder al título de maestro de obras y los que lo hicieron al de arquitecto o, lo que era en un principio lo mismo a finales del siglo XVIII y en los inicios del XIX, la denominación hibrida de maestro de arquitectura. Aquellos tenian una formación cotidiana bastante más práctica, pues muchos de ellos se habían ejercitado en la albañilería antes de concurrir a la Academia. Algunos eran hijos o familiares de maestros de obras, habiéndose educado en la profesión, sobre todo, junto a sus padres y parientes, tal y como solía ocurrir en el sistema gremial. Además, varios de ellos se presentaban ya con una edad bastante madura con la finalidad de regular oficialmente su profesión. Acreditaban haber ya participado en la construcción de muchas obras. Por el contrario, los aspirantes al título de arquitecto, obviamente, tenían una mejor formación teórica, pues habían concurrido, tal y como ya se ha indicado antes, o a las Academias o a la Escuela de la Lonja, o a una Universidad...; pero su práctica profesional casi siempre era algo o demasiado escasa.

También se perciben varias diferencias entre unos y otros en estas pruebas de pensado. Los informes de los maestros de obras suelen ser bastante más escuetos y directos, y se centran, sobre todo, en el método constructivo y en el empleo de los distintos materiales. Presentaban menos diseños del proyecto, que solían ser más sencillos, realistas y modestos en sus pretensiones, pues se destinaban a ciudades de segunda categoría, que el de los arquitectos, a veces demasiado ideales y hasta un tanto utópicos. Por el contrario, éstos debían dibujar muchas más plantas, fachadas y secciones que aquéllos para dejar todo muy claro y preciso. Eran pretensiosos y habían de demostrar hallarse al día en los modelos de cárceles. Ibáñez, Carrillo, Barrenechea, Loitia, Zayas, Umbert y Morera pretendian el título de maestro de obras. Los demás aspiraban al de arquitecto, excepto Barra, cuya prueba disertativa o literaria era para el grado de incorporación a la Academia de académico de mérito55.

Las diferencias entre ambos profesionales también se perciben en las preguntas, que los integrantes del tribunal examinador los hacían en la prueba final, que era la oral. Las de los maestros de obras resultan bastante más prácticas: tipo de bóvedas y modo de construirlas, construcción de vertientes de tejados, medición de sólidos, método práctico de sacar plantillas para construir mampostería, modo de echar cimientos, sistema 
para construir aljibes... Antes, la junta de profesores habia comparado la prueba de repente con la de pensado para comprobar que ambas eran suyas, de su propia mano, o si alguien le había dibujado esta última. Las preguntas realizadas por este tribunal se relacionaban una a una por escrito en el acta del correspondiente examen, al igual que el informe redactado por cada profesor del tribunal, siendo ambos guardados en el Archivo de la Academia junto al expediente.

Algunos de estos aspirantes tuvieron serios problemas durante los exámenes. Por ejemplo, Miguel Umbert, natural de Mataró y con mucha práctica a sus espaldas, tuvo problemas con la lengua castellana, pues no entendió algunas de las preguntas que los profesores le hicieron en el examen oral en 183556. Ante la duda de los profesores examinadores por aprobarlo o suspenderlo, resolvió que decidiese la correspondiente junta ordinaria de la Academia.

También, el granadino Gago tuvo problemas con su fecha exacta de nacimiento, que aparecia raspada en la correspondiente partida adjunta, motivo por el cual la Academia pidió nueva certificación, pues los pretendientes a los títulos de la arquitectura no podian presentarse a examen sin tener antes cumplidos los veinticinco años de edad57. Pero, además, este joven tan utilitario en su proyecto utópico de cárcel para fundición de cañones, no fue capaz de pasar el examen oral en 1845. Después atribuyó su fracaso a su estado de melancolía debido a graves problemas familiares. Es de notar que, si dibujando certificaría una gran capacidad, no ocurrió lo mismo en su informe facultativo del proyecto, donde demostró demasiada falta expresiva y laconismo. Sin duda, Gago dibujaba mucho mejor que escribia y hablaba.

Miguel Geliner (lám. 10) comprobó cómo su impresionante panóptico, casi un bello cuadro abstracto, era rechazado por los profesores de una exigente Comisión de arquitectura58. Su proyecto resultaba demasiado ideal para realizarse, y, además, no lo explicaba suficientemente en su correspondiente informe, que se juzgó como demasiado general. Él mismo reconoció después el error y presentó nuevos diseños como prueba de pensado, que ahora eran mucho más realistas: una casa Aduana, unos lavaderos para una capital de provincias y una iglesia parroquial. Es el único caso de rechazo del diseño de una cárcel en la Academia madrileña, lo cual demuestra su gran benevolencia.

56 Umbert, AASF: leg: 17-6/2.

57 Gago, AASF: leg. 14-1/2bis.

58 Geliner, 10-3/2bis. 


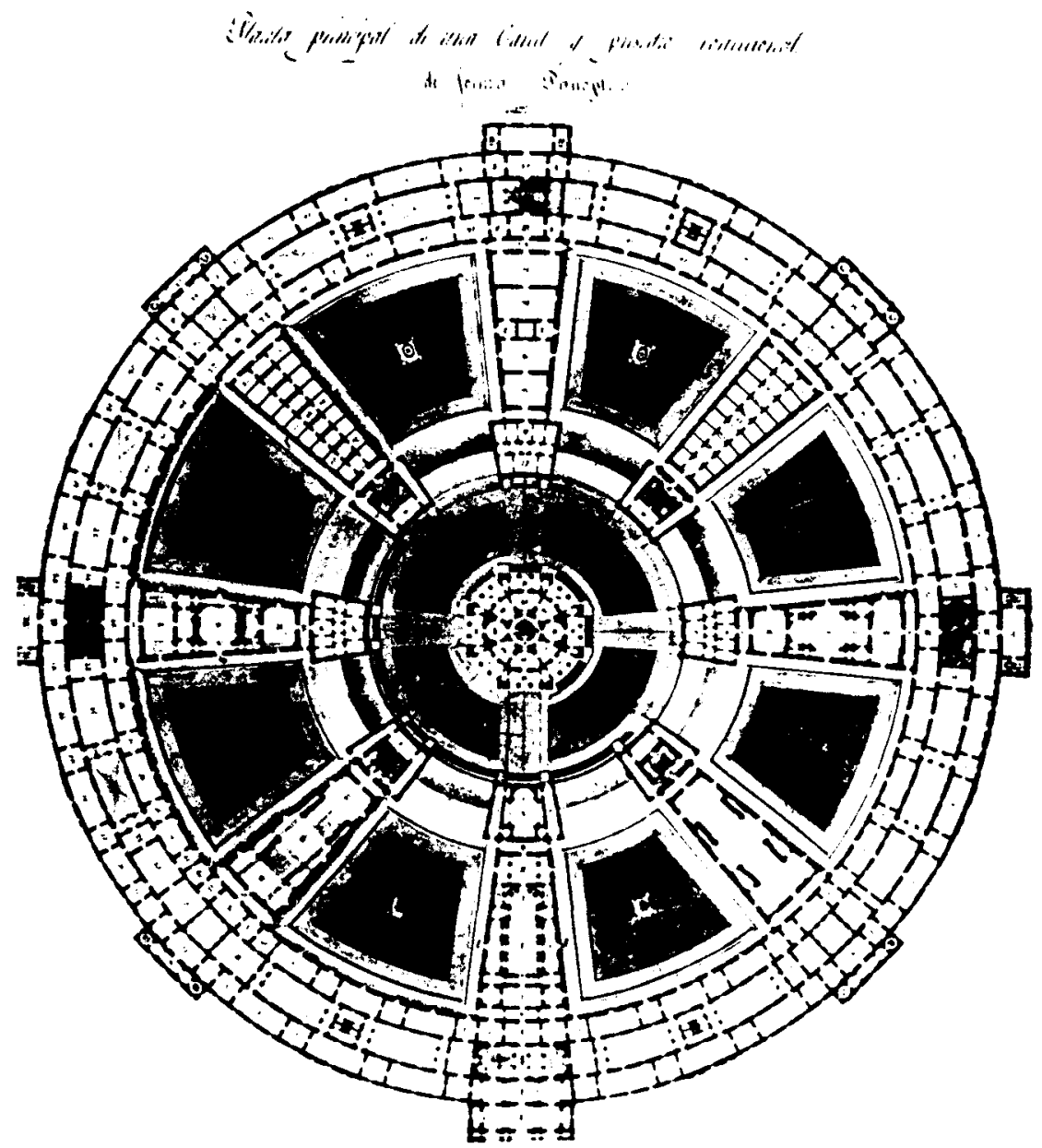

Lám. 10 Planta de cárcel y presidio correccional. Proyecto de Miguel Geliner y Gelma, discípulo de José Oriol y de Antonio Celles. 1838. AASF: Planos: A-981. Leg: 10-3/2 bis.

\section{Una "vieja novedad»: la redefinición de una tipología hasta en-} tonces algo desdibujada

En la arquitectura de cárceles la referencia a la Historia quizá tuviera entonces bastante menos interés que en otras tipologías arquitectónicas como, por ejemplo, el mismo teatro. En éste había ya una larga y amplia tradición de modelos, que, partiendo de la época griega y del paradigma codificado por Vitruvio se desarrolló durante el Renacimiento al deber 
adecuarse de un espacio abierto a un recinto cerrado, sobre todo, con Alberti y Palladio. A ello había que añadir los modelos del barroco académico de Carlo Fontana y sus diversas opciones, a Juvarra, los rococós de los Bibiena, los clasicistas de Milizia y Patte... Habia muchos más modelos alternativos salidos del pasado y de aquel presente en el teatro que en la misma cárcel. De aquí que el historicismo esté más manifiesto en aquél que en esta última, pues Vitruvio no prestó ninguna atención al presidio, localizándolo tan sólo en el foro de la ciudad. Alberti intentó sistematizar un modelo, pero sin aludir a la cultura grecorromana, pues no tenía demasiadas referencias tomadas de la Antigüedad. La cárcel aparece relacionada con el palacio fortificado y con el mismo cuartel; pero también puede aludir al convento y al hospital, y hasta al teatro, lugar espectacular para el espectáculo. Se podría considerar, así, como una síntesis de varias tipologías, en las cuales se basa, pues se inspira en ellas, de las que toma diversos elementos.

Por tal motivo esta tipología, hasta entonces demasiado desdibujada desde una perspectiva histórica y quizá bastante más literaria que arquitectónica, fue, en cierta manera y de una forma paradójica, una «vieja novedad" en los albores del sigio XIX por la falta de modelos significativos y específicos, que no fuesen los diseñados durante la misma llustración tan próxima en el tiempo. Tal vez por ello suscitó un gran interés en el transcurso de la primera mitad de la centuria, fruto del humanismo ilustrado, que vio surgir una serie importante de posibilidades a través de los nuevos ejemplos. Seria entonces cuando realmente se definió como tipologia arquitectónica con unas caracteristicas propias, que eran la consecuencia de una nueva forma de entender, la ilustrada, la normativa jurídica. Así, las ideas de humanizar la cárcel, de clasificación por distintos sexos, edades y delitos cometidos, del trabajo como forma de pagar o redención de las penas, de reintegración social por medio del aprendizaje de un oficio y de mantenimiento del presidio a través de un sistema productivo, de la enseñanza religiosa en calidad de elemento de reforma moral..., reincidieron en la arquitectura, que habria de adecuarse a todos y cada uno de estos objetivos. Pero, además, intervino en la formación plena de esta tipología la necesidad de ver, y hasta de oír, cuanto pasaba en el interior de la cárcel y en las mismas celdas a todas las horas del día. El "ojo» del guardián, tan sólo comparable con la presencia divina, debía estar siempre omnipresente para evitar nuevos delitos. La óptica incidió en la forma de la planta, como en el teatro y hasta en el hospital. La introvertida cárcel viene a ser en algo cual un teatro invertido, donde una muchedumbre de presos se convierten en espectáculo para unos pocos vigilantes $y$, también, donde el escenario es la platea y la platea es el escenario. 
La cárcel formó su especificidad gracias al auxilio de otras tipologías arquitectónicas ya bastante más definidas como tales. El palacio y el cuartel fueron una importante referencia inicial, cual también lo había sido el mismo convento; pero, sobre todo, el hospital la prestó muchas de sus características para lograr la clasificación de los presos de forma similar a la de los enfermos - el delito se percibía como una enfermedad moralpor el sistema de pabellones aislados. Asimismo, incidió la situación central de la capilla para que los oficios pudieran ser vistos y oídos por todos. Del teatro se tomó el concepto óptico: era preciso contemplar cuanto ocurría en su interior. Asimismo incidió en una apreciación escenográfica del presidio. Pero hasta el sonido también debía controlarse.

Los diseños de los proyectos de cárceles realizados por los aspirantes a los títulos académicos de la arquitectura certifican el interés por esta tipología en la España de la época. Se dibujaron siguiendo distintos ejemplos -los de Gante, Filadelfia, Bentham, la celular...- apareciendo a veces submodelos, pues se introdujeron algunas variaciones notables en ellos. Obedecen a la inquietud existente en la Academia por estas tres tipologias ópticas y, también, acústicas: el teatro, el hospital y la cárcel, de las que se conservan muchos dibujos en su Gabinete de Estampas. Prueba de ello es el libro de Marcial Antonio López, secretario de tal instituto, describiendo modelos de cárceles.

La falta de suficientes referencias clásicas y muy concretas sobre el presidio, su misma condición de estar aún algo desdibujada, facilitó su grado de modernidad. Apenas existían precedentes modélicos, motivo por el cual era posible hacer, más que recrear, e introducir las novedades más importantes. No obstante, en ocasiones se citaba ese clasicismo, que en la romántica primera mitad del XIX racionalmente se habia convertido en funcionalista. Pero en la cárcel apenas había lugar para el empleo de los órdenes a no ser en sus escasos espacios nobles. Además, en España ninguna otra tipología podía seguir tanto como en la cárcel las machaconas recomendaciones académicas de desornamentación y economía. Al final todo se mide económicamente. 